Chapter 7

\title{
Gastric Carcinoma: Morphologic Classifications and Molecular Changes
}

\author{
Sun-Mi Lee, Kyoung-Mee Kim and Jae Y. Ro \\ Additional information is available at the end of the chapter \\ http://dx.doi.org/10.5772/54617
}

\section{Introduction}

Gastric cancer is the second leading cause of cancer death and the fourth most prevalent malignancy worldwide, affecting about one million people per year [1]. In the United States, an estimated 21,320 cases of gastric cancer (13,020 men and 8,300 women) will be diagnosed and 10,540 patients will die from this disease in 2012 [2]. The overall incidence of gastric cancer in the United States has been steadily declined over the past 75 years. Based on National Cancer Institute's Surveillance, Epidemiology, and End Results (SEER) cancer statistic data from 2005 to 2009 , it is estimated approximately 1/114 men and women will be diagnosed with gastric cancer during their life; most people diagnosed with gastric cancer are over 65 years of age and men have higher gastric cancer incidence and mortality rates than women [3]. Asians/Pacific Islanders have the highest incidence as well as high mortality rates. The incidence of gastric cancer is exceptionally high in Northeast Asia, including Japan and South Korea, probably as a consequence of genetic factors and active screening policies [4]. Central Europe and South America also show a higher incidence rate of gastric cancer than the United States and Northern and Western European countries [5]. In addition to the geographic, ethnic, racial and genetic differences on the incidence of gastric cancer, environmental factors such as a high infection rate of Helicobacter pylori in Northeast Asia, also play an important role [6].

The significant improvement and widespread use of upper gastrointestinal endoscopy have led to early detection of gastric cancer. Early gastric cancer represents approximately $20 \%$ of all newly diagnosed cancer in the United States and up to $60 \%$ in Japan and South Korea [7, 8]. Marked advances in endoscopic procedures such as endoscopic mucosal resection (EMR) and submucosal dissection enhance a dramatic clinical therapeutic impact on the mortality rate and quality of life after procedures. Now gastric cancer is considered as a potentially 
curable cancer at an early stage. Moreover, modern targeted therapies for gastric cancer using trastuzumab suggest a promising progress in treatment and clinical outcome even in an advanced stage.

Data on topographic distribution of esophageal and gastric cancers since 1976 indicate that cancers of distal esophagus, gastroesophageal junction (GEJ), and gastric cardia have been increased in incidence with the reverse in incidence of the distal gastric cancers [9]. Now, adenocarcinomas of proximal stomach (upper third) account for approximately $30 \%$ of all gastric cancers and its clinical impact becomes more important. Although active and vivid clinical trials have been ongoing on to seek effective therapeutic modalities for GEJ and gastric cardia adenocarcinomas, there has been no universal consensus classification of these disease entities into one over the other, gastric carcinoma vs. esophageal carcinoma, due to lack of standard definition of GEJ and cardia as an anatomic site [10]. The International Classification of Diseases and Siewert classification system have shown different categorizations of the origins of these tumors into esophageal or gastric cancer. In the recently published seventh edition of the Cancer Staging Manual of the American Joint Commission of Cancer, however, tumors of the GEJ and gastric cardia are included under the esophageal carcinoma [11]. The debate on this categorization is still ongoing, especially for general surgeons $[12,13]$.

\section{Adenocarcinoma of gastroesophageal junction}

Despite dramatic decrease in incidence of distal gastric cancer with a better clinical outcome, the incidence of adenocarcinomas of the distal esophagus, GEJ, and gastric cardia has been increased from $4 \%$ to $10 \%$ per year in the United States, predominantly in men since 1976 [9, 14-16]. In Japan, the proportion of these tumors has also increased among men over last 15 years [17]. This epidemiologic trend has an important clinical influence because adenocarcinomas of the GEJ and gastric cardia showed much worse prognosis than that of distal gastric cancer, with 5 -year survival rates in the range of $14 \%$ to $22 \%$, and minimal chemotherapeutic response in an advance stage [18, 19]. Moreover, there has been no established consensus for the classification of these tumors and therapeutic modalities including lymphadenectomy, the extent of surgical resection, and chemotherapy $[20,21]$. In addition, some studies have demonstrated that adenocarcinomas of the cardia have different clinicopathologic characteristics compared to adenocarcinomas of distal stomach such as a higher male to female ratio, different ethnic background, a history of chronic heartburn or duodenal ulcer, and association with smoking and alcohol drinking $[22,23]$. Furthermore, adenocarcinoma of the gastric cardia shows a greater tendency to invade deeply into the gastric wall and frequent lymph node metastasis with a worse prognosis [24-26].

Although the main cause of the increasing rate of GEJ cancer is controversial, previous studies demonstrated that these tumors were significantly associated with symptomatic reflux disease and suggested that GEJ cancers are more likely arising from the distal esophagus than from the stomach $[27,28]$. In addition to symptomatic reflux disease as a risk factor, 
recent studies from Japan demonstrated that Helicobacter pylori infection appeared to be also correlated with GEJ cancers in the Helicobacter pylori infection endemic areas [29].

In 1998, Siewert and Stein have proposed the new classification of GEJ cancers based on their anatomic sites with estimated origins. This system divides these tumors into three types as follows: type I, distal esophageal adenocarcinoma with the epicenter of the tumor lying $2.5 \mathrm{~cm}$ above the cardia; type II, cardiac adenocarcinoma that the tumor straddles the GEJ with the epicenter in the region $1 \mathrm{~cm}$ above or $2 \mathrm{~cm}$ below the cardia (Fig.1); and type III, subcardiac adenocarcinoma with its epicenter $2-5 \mathrm{~cm}$ below the cardia [30].

In the International Classification of Disease recently, however, adenocarcinomas arising in the distal third of the esophagus and those that straddle the GEJ are grouped with tumors of the gastric cardia and all these tumors assign under the category of gastric adenocarcinoma [31].

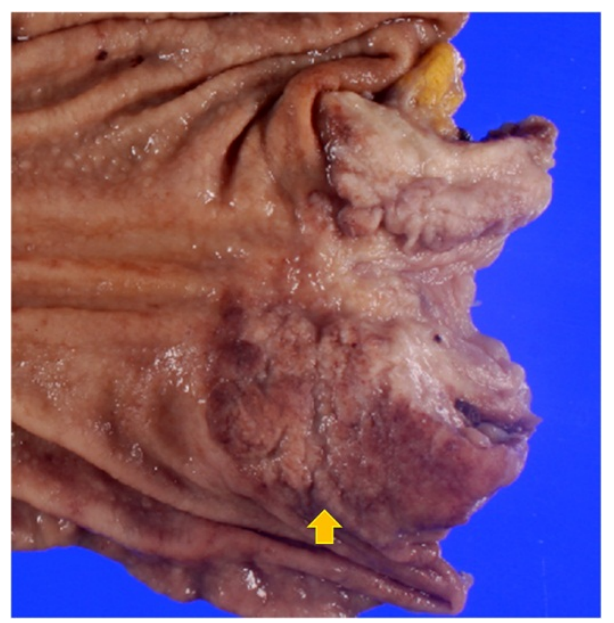

Figure 1. Siewert type II gastroesophageal junction carcinoma. The tumor is ill defined and irregularly elevated (yellow arrow). It involves cardia and distal esophagus, which exactly straddles the gastroesophageal junction.

The current $7^{\text {th }}$ edition of the AJCC TNM classification of malignant tumors provided rules for classifying adenocarcinomas of distal esophagus, GEJ, and gastric cardia [11]. According to this system, any tumors with an epicenter within $5 \mathrm{~cm}$ of the GEJ and tumors which extend into the distal esophagus are to be classified as esophageal carcinomas and staged as such. It means that all other tumors at the GEJ with an epicenter in the stomach $>5 \mathrm{~cm}$ from the GEJ or those within $5 \mathrm{~cm}$ of the GEJ without extension into the esophagus are to be classified and staged as gastric carcinomas. Therefore, most of type II cardiac and type III subcardiac adenocarcinomas by Siewert are now staged as esophageal adenocarcinomas (Fig.2). In a recent clinical study, the prevalence and distribution of lymph node metastasis in patients with adenocarcinoma of the distal esophagus and GEJ cancers were similar after esophagectomy and there was no difference in overall survival or recurrence between these two groups of cancers. Based on this study, 
they reported that an effort to separate these two groups of the tumors is not required, and both are effectively treated with esophagectomy [32]. However, in the series by Gertler et al, 1141 patients with type II cardiac and type III subcardiac adenocarcinoma were reclassified following the current TNM system and compared two different categorization schemes of cardiac and subcardiac adenocarcinoma as esophageal or gastric cancer and concluded that neither of the two staging systems proved to be clearly superior over the other [33]. Thus, the categorization of cardiac and subcardiac adenocarcinoma (type II and III by Siewert) into esophageal or gastric cancers, respectively or independent disease entity needs to be evaluated further in the near future.

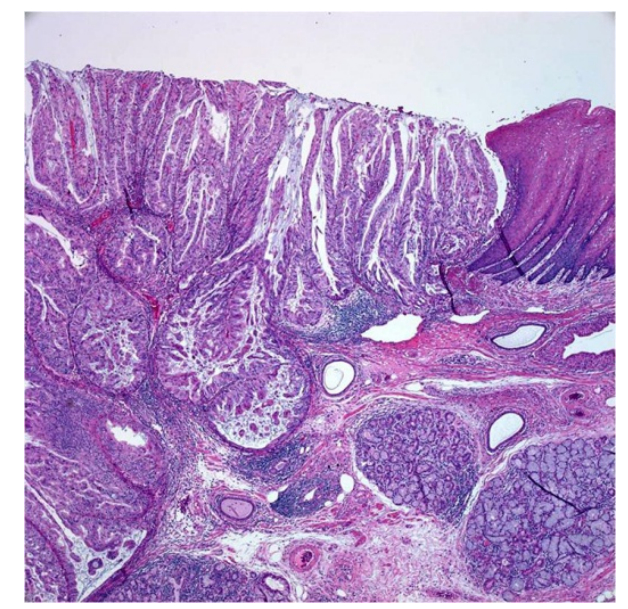

Figure 2. Gastroesophageal junction carcinoma without Barrett's esophagus. Well differentiated papillary adenocarcinoma infiltrates into the submucosa of the esophagus without evidence of Barrett's esophagus in the overlying mucosa.

\section{Early gastric carcinoma}

\subsection{Definition, epidemiology and clinical manifestation}

Early gastric carcinoma (EGC) is defined as an invasive adenocarcinoma that involves only the mucosa or submucosa but not the muscularis propria, independent of lymph node status [34]. The term, EGC, implies not only the limited extent of the disease but also an early stage in development and a less aggressive neoplasm, which carries an excellent prognosis if the lesion is completely removed [35]. Nowadays EGC represents approximately $20 \%$ of all newly diagnosed gastric cancers in Western countries, whereas in Northeast Asia (Japan and Korea), it accounts for over 50\% of cases [36]. The difference in incidence between Northeast Asia and Western countries may be due to a higher prevalence of gastric cancer 
with mass screening test, and widely adapted use of magnifying upper endoscopy with high-resolution images and chromoendoscopy in Northeast Asia.

Most patients with EGC are diagnosed at a median age of 63 (range 21-89) years and men are affected more than women like other types of gastric cancer (male to female ratio, $1.4-2.4: 1$ ) [37-40]. The majority of patients with EGC are asymptomatic, but some may present with non-specific upper abdominal symptoms such as heartburn or epigastric pain, so-called dyspeptic symptoms. Weight loss, anorexia, anemia, and hypoalbuminemia frequently found in patients with advanced gastric cancer are not commonly seen [41]. Dyspeptic symptoms may occur in up to $40 \%$ of the patients with EGC [42]. Sometimes, dyspeptic symptoms may be an important clue for the detection of EGCs [39]. However, dyspeptic symptoms related with EGC can be easily masked by the use of anti-acid drugs such as cimetidine or proton pump inhibitors [43, 44]. Many EGCs are believed to go through a cycle consisting of ulceration, followed by healing, and reulceration [45]. It suggests that EGC can be partially healed by acid suppression, which makes difficult to diagnose EGC endoscopically because it mimics a benign peptic ulcer. Therefore, it is strongly recommended that patients with dyspeptic symptoms should undergo an endoscopic procedure with biopsy at least once after the symptoms are relieved by medication.

EGC is regarded as an early stage lesion in development that can progress to an advanced lesion [35]. One prospective study on EGCs reported that the median duration for tumor progression is approximately 3.7 years [46]. However, some EGCs can show a rapid progression into advanced lesions within a year [47]. Generally, EGCs are considered to be curable if the lesion is completely removed by endoscopic resection or surgery. Most of Japanese series have reported more than $90 \%$ of 5 and 10 year survival rates for the patients with EGC [48, 49]. In the Western series, 5-year survival rates are variable, ranging from $68 \%$ to $92 \%$ [8, 38-40,50]. EGCs can recur at least $1.9 \%$ of cases after resection with intervals ranging from 4 months to more than 10 years, with important risk factors for the recurrence including the presence of submucosal invasion, nodal metastasis, and undifferentiated histology [51].

\subsection{Methods for evaluation and staging of EGC}

Double-contrast barium upper gastrointestinal series have been used to detect gastric cancer over the past two decades. However, this study has a limitation to detect small EGCs. For the lesions of EGC between 5 and $10 \mathrm{~mm}$ in diameter, false negative rates are as high as $25 \%$ [52]. Endoscopy is the procedure of choice and should be performed on all patients in whom the diagnosis of gastric carcinoma is suspected. The endoscopic findings favoring an EGC associated ulcer include: (1) disruption and clubbing of the surrounding mucosal folds, (2) a dirty appearance of the surrounding mucosa with adherent mucus or exudates, (3) irregular margins of the ulcer itself, and (4) island-like residues of intact mucosa within the depressed area [53].

EGCs can be divided into two subtypes depend on the depth of invasion; intramucosal and submucosal invasive adenocarcinomas. The status of submucosal invasion in EGC is critical 
for determining the treatment option, surgery vs. endoscopic resection and estimating a risk of lymph node metastasis that is directly related with a clinical outcome. The 5-year survival rate for intramucosal invasive EGC is close to $100 \%$, whereas for submucosal invasive EGC is from $80 \%$ to $90 \%[54,55]$. Therefore, active trials are ongoing in Japan and South Korea to detect the submucosal invasion in EGCs preoperatively by endoscopy and endoscopic ultrasonography (EUS). Different endoscopic features of intramucosal and submucosal gastric carcinoma have been investigated for an accurate local staging. Choi et al demonstrated that intramucosal gastric carcinoma was endoscopically characterized by smooth surface protrusion or depression, erosion, or marginal elevation [56]. In contrast, submucosal gastric carcinomas usually showed distinct endoscopic features with fold convergence (clubbing, fusion, abrupt cutting) and nodular protrusion/depression [57]. EUS is now widely used for substaging of EGCs. The overall accuracy rates for staging the depth of invasion of EGCs by endoscopy and EUS were reported $72.2 \%$ and $64.8 \%$, respectively [58]. The diagnostic accuracy of EUS for the depth of invasion can be significantly affected by EGC with undifferentiated histology and large tumor size [59].

\subsection{Gross features}

EGCs vary greatly in size raging from microscopic foci to $5 \mathrm{~cm}$, but larger lesions up to $7 \mathrm{~cm}$ in diameter are not unusual $[38,60,61]$. These large tumors are typically located in the antrum, around the angle, with predominance in the lesser curvature $[40,60]$. The larger EGCs have a tendency to frequently invade into the submucosal layer, however, some studies demonstrated minute EGCs can also invade into the submucosa in $3.3 \%$ to 9\% of cases [62-64]. EGCs can be found as multiple lesions in the background of intestinal metaplasia. In recent series, more than half of synchronous gastric carcinomas were EGCs, frequently in elderly patients, with the incidence of multiple synchronous EGC ranges from $3.7 \%$ to $7.7 \%[65,66]$. Oohara et al and Hirota et al demonstrated that synchronous EGCs are macroscopically flat and small lesions, rarely infiltrate into submucosa and can be easily missed in preoperative endoscopic or intraoperative evaluation (Fig. 3) $[67,68]$. Although it is well known that EGCs rarely metastasize to other organs, Ishida et al reported that 15 (0.6 \%) of 2,707 patients with EGC developed liver metastasis, especially in patients with submucosal invasion, macroscopically elevated type, and with vascular invasion [69].

The endoscopic or macroscopic classification of gastric cancer established by the Japanese Gastric Cancer Association has now been accepted worldwide and was endorsed at an international workshop in Paris in 2002 [70]. Particularly, this Japanese classification system based on endoscopic findings of EGCs has been known to be useful to be employed for the endoscopic procedures. EGCs are classified into three different subtypes according to the morphologic appearance of the lesion on the mucosal surface as follows: type I (protruding type, polypoid tumors), type II (superficial tumors with or without minimal elevation or depression) and, type III (excavated type, tumors with deep depression) (Fig 4). Type I EGC is a tumor that protrudes above the mucosal surface more than 2.5 $\mathrm{mm}$ in height. Tumors with type II are further subdivided into three subtypes depend 
on the degree of elevation or depression compared to the imaginary horizontal line from both ends of the normal surrounding mucosa as follow: type IIa (superficial elevated), type IIb (superficial flat), and type IIc (superficial depressed) (Fig 5). Type IIa EGCS is defined as a lesion that is twice as thick as normal mucosa, but less than or equal to 2.5 $\mathrm{mm}$ in height [71]. The distinction between type I from IIa EGC depends on the extent of elevation: if the height of the lesion $>2.5 \mathrm{~mm}$, it is regarded as type I, and if $\leq 2.5$ $\mathrm{mm}$, then it is type IIa [42]. Type Ilb lesions represent $58 \%$ of minute EGCs measuring < $5 \mathrm{~mm}$ in size and are the most difficult type to diagnose endoscopically [52, 72]. Therefore, multiple sampling is highly recommended for an accurate histopathologic diagnosis when the lesion is suspicious for type IIb EGC. Type III lesions are characterized by prominent depression and, ulcer-like excavation (Fig. 6). Many EGCs may have a combination of different macroscopic types, i.e., IIc+III and IIa+III. Type II EGCs account for approximately $80 \%$ of cases with type IIc being the most common macroscopic subtype [73]. In the series by Craanen et al, types I and IIa lesions are likely to represent the intestinal type, whereas diffuse-type EGCs are likely to be types of IIc or III lesions [74]. They also described that specific endoscopic types of EGCs are associated with a risk of lymph node metastasis, with the lowest rates reported in type I or IIa EGC.

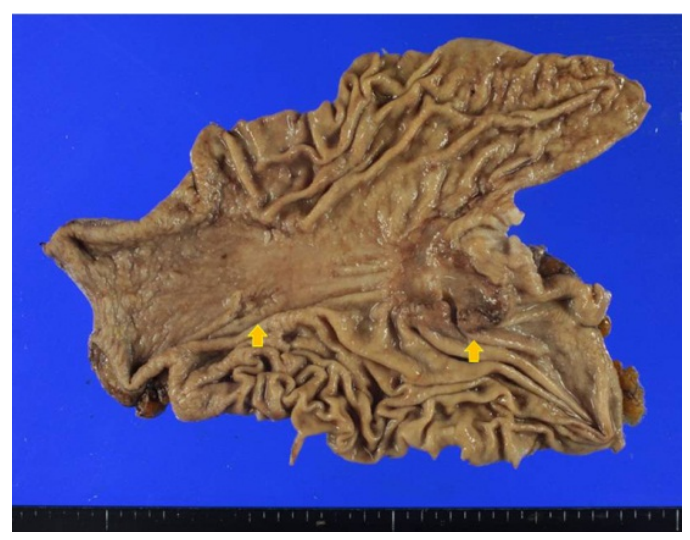

Figure 3. Multiple gastric carcinomas case. An ulceroinfiltrating Bormann type 3 gastric carcinoma is located in the subcardia (right yellow arrow). In the antrum of lesser curvature, additional small type Ila+llc early gastric carcinoma (left yellow arrow) is found. The surrounding gastric mucosa shows diffuse atrophic changes. 


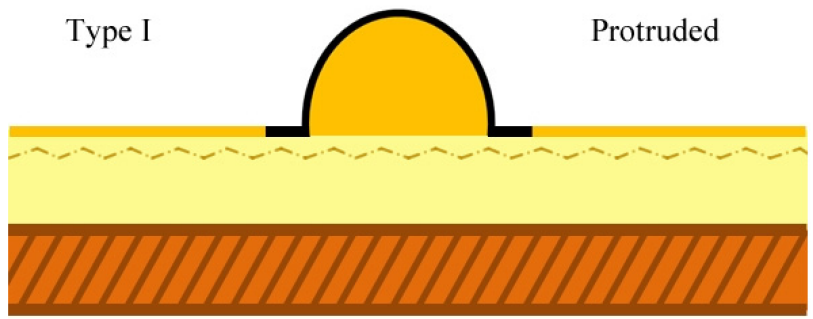

Mucosa

Submucosa

Muscularis

propria

Type IIa

Superficial Elevated

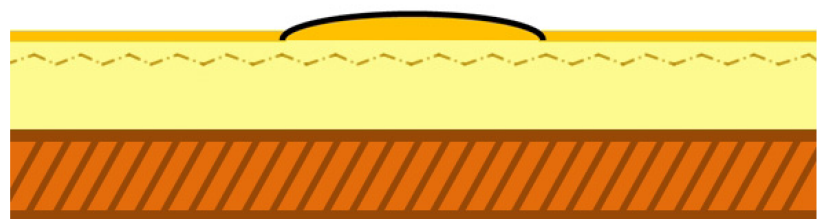

Mucosa

Submucosa

Muscularis

propria

Type IIb

Flat type

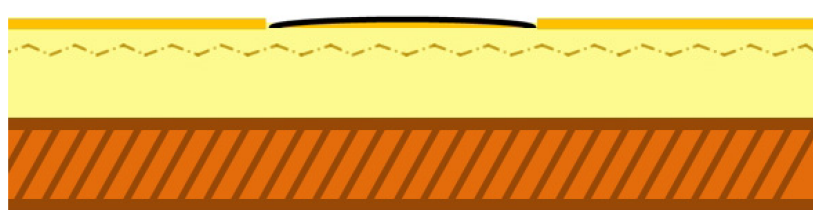

Mucosa

Submucosa

Type IIc

Superficial depressed

Muscularis

propria

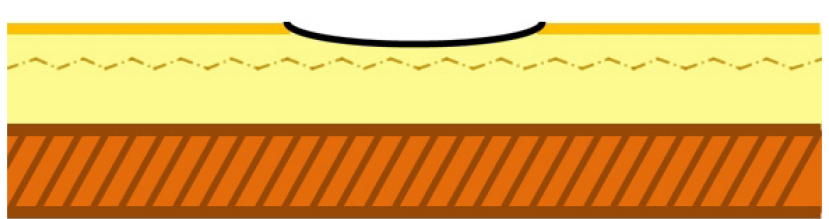

Mucosa

Submucosa

Muscularis

propria

Type III

Excavated

Mucosa

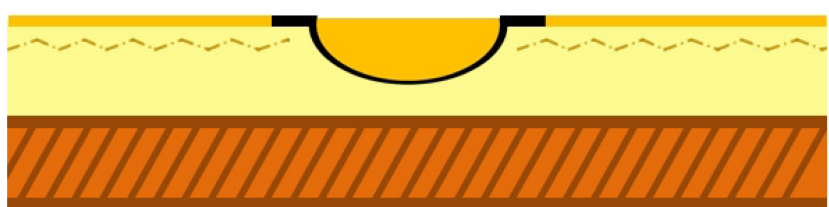

Submucosa

Muscularis propria

Figure 4. Japanese macroscopic classification of early gastric cancer 

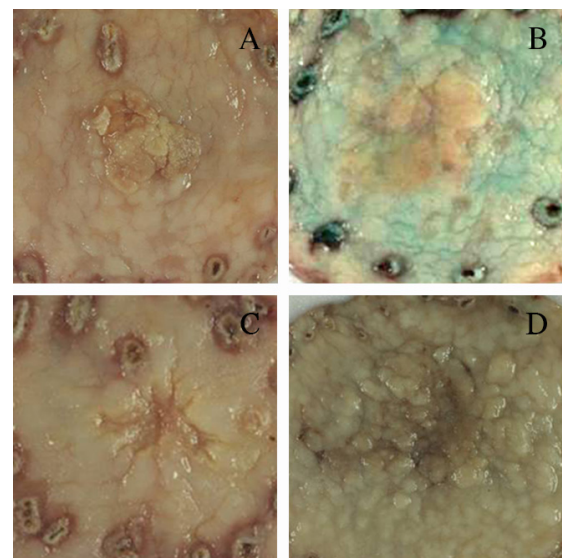

Figure 5. Early gastric cancer. A: EGC type I. The tumor shows a protruding lesion more than $2.5 \mathrm{~mm}$ in height. B: EGC type Ila. The tumor shows a slightly elevated, plaque-like lesion. C: EGC type IIc. A slightly depressed lesion with an irregular ulcer base mimicking a benign ulcer is seen. D: EGE type IIb+llc. A combined flat and depressed lesion is accompanied with surrounding nodular gastric mucosa.

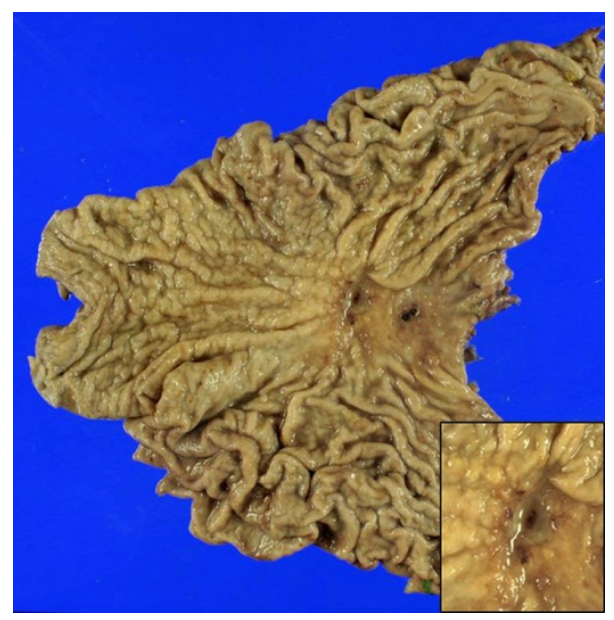

Figure 6. EGC type III. An ulcer-like excavated lesion with a prominent depression is present in the body of the lesser curvature.

\subsection{Microscopic features}

Histologically, the majority of EGCs are well differentiated, tubular adenocarcinomas. Most of the lesions are intestinal types with predominantly tubular (93\%) and papillary (1\%) histology (Fig.7) [73]. Mucinous carcinomas account for 1\% of all EGCs. Signet ring cell carcinomas and poorly differentiated adenocarcinomas represent $5 \%$ and $30 \%$ of the 
cases, and are usually depressed or ulcerated types (types IIc or III) [73, 75] (Fig 8). Severe atrophic gastritis with diffuse intestinal metaplasia and pre-existing adenoma are frequently seen in the background of adenocarcinoma. It has been estimated that $10 \%$ of individuals with chronic atrophic gastritis would develop gastric carcinoma in a 15-year follow-up period [76].
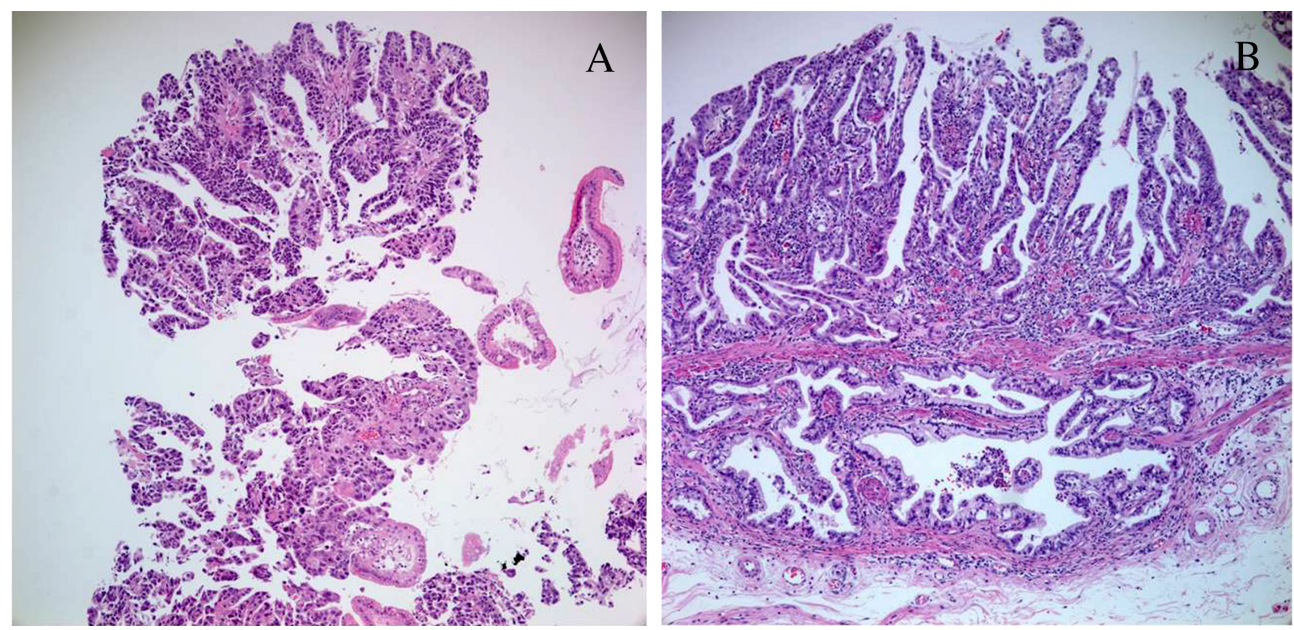

Figure 7. A. The biopsy shows well- differentiated papillary adenocarcinoma with invasion into the lamina propria. B. The endoscopic submucosal dissection specimen shows that the tumor invades into submucosa.
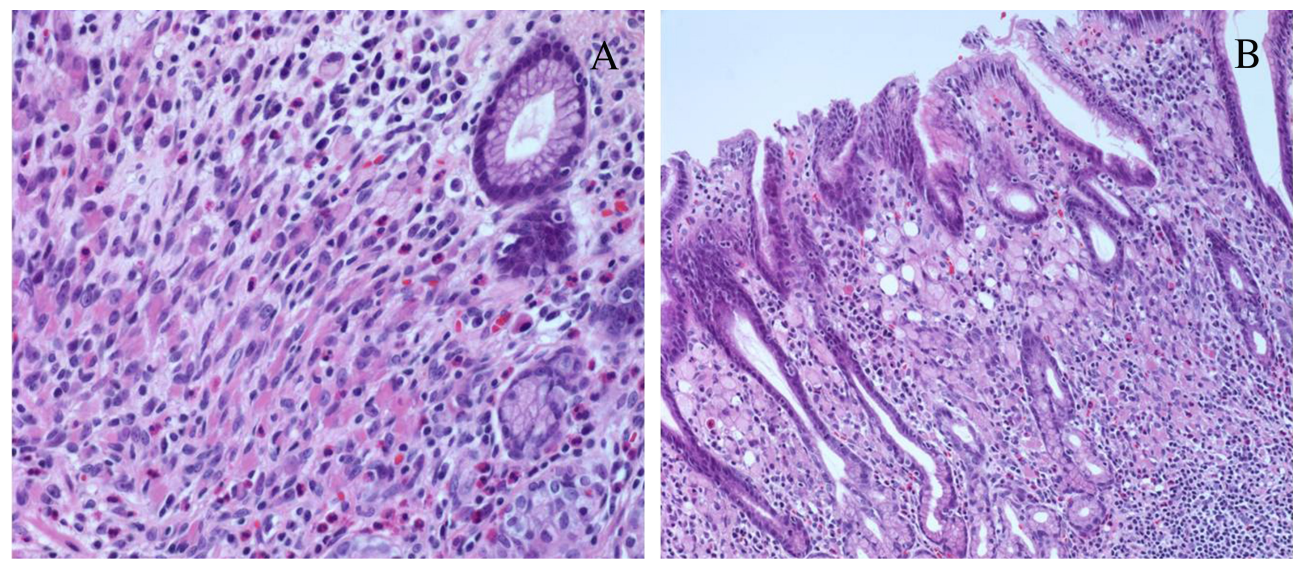

Figure 8. A. Intramucosal signet ring cell carcinoma with eosinophilic cytoplasm. B. Goblet cells mimicking signet ring cell carcinoma are found in the same gastrectomy specimen. 
There has been a disagreement between Western and Japanese pathologists in distinguishing between high grade dysplasia and intramucosal invasive adenocarcinoma of the stomach. In the United States and Western countries, intramucosal invasive adenocarcinoma of the stomach has been defined as a lesion that shows clear invasion of the lamina propria in the form of single cells or small clusters of cells and a diagnosis of high grade dysplasia is rendered when the lesion shows only cytologic atypia and architectural abnormalities without clear invasion [77]. However, for Japanese pathologists, a diagnosis of intramucosal invasive adenocarcinoma has also been made with cytologic atypia and architectural abnormalities as parts of diagnostic criteria for intramucosal invasive adenocarcinoma in addition to intramucosal invasion by tumor [78]. This discrepancy of diagnostic criteria between Japanese and Western pathologists had developed a new Vienna classification for gastric epithelial neoplasia; however, this classification has not been adopted widely.

\subsection{Indications for endoscopic resection}

In a meta-analysis of 5,265 patients with EGC who underwent gastrectomy with lymph node dissection, nodal metastasis was observed in only $2.7 \%$ of adenocarcinomas with invasion limited to the mucosa and in $18.6 \%$ of EGCs with invasion extending into submucosa [79]. This seminal paper induced the widespread application of EMR as a first-line therapy for EGCs meeting several criteria, as underscored by the Japanese Gastric Cancer Association. The current indication of EMR for the treatment of EGCs includes well or moderately differentiated adenocarcinoma histology. The lesions must be (1) confined to the mucosa; (2) smaller than or equal to $2 \mathrm{~cm}$ for superficially elevated type lesions; (3) smaller than or equal to $1 \mathrm{~cm}$ for the flat and depressed type lesions; (4) no ulcer or ulcer scar; (5) no venous or lymphatic involvement [80, 81]. However, EMR has a limitation to resect a lesion greater than $2 \mathrm{~cm}$ in size and a relatively high risk of local recurrence up to $35 \%$ when resected tissues are fragmented or margins are not clear [82]. Thus, a new technique of endoscopic submucosal dissection (ESD) was recently developed to dissect directly along the deep submucosal layer, facilitating one-piece resection. After the introduction of ESD, some institutions in Japan and Korea have tried to adopt the expanded criteria for ESD. The expanded criteria for ESD include intramucosal EGS without size limitation for resection (elevated type), tumor with differentiated type as well as undifferentiated type $(\leq 2 \mathrm{~cm})$, and an ulcerative lesion $(\leq 3 \mathrm{~cm})$ [83]. The classic and expanded criteria for EMR and ESD are listed in table 1. Recently, Hirasawa et al investigated 3,843 patients of solitary undifferentiated type EGC with status post gastrectomy and lymph node dissection to find clinicopathologic factors related with lymph node metastasis [84]. They found that none of 310 intramucosal invasive EGCs with $2.0 \mathrm{~cm}$ or less in size without lymphovascular invasion and ulcer was associated with lymph node metastasis, which supports the expanded criteria for the endoscopic resection. In addition, in large series by Ahn et al, patients with EGC underwent an ESD with the extended criteria have shown acceptable clinical outcomes with a relatively high complete resection (88.4\%) and a low local recurrence rate (1.1\%) [85]. Careful clinical and radiographic evaluation using endoscopy and EUS for an accurate local staging and an appropriate selection of patients are strongly recommended before the application of the expanded criteria for ESD. 


\begin{tabular}{|c|c|c|c|c|c|c|}
\hline \multirow[b]{3}{*}{ Size $(\mathrm{mm})$} & \multicolumn{4}{|c|}{ Intramucosal Carcinoma } & \multicolumn{2}{|c|}{ Submucosal Carcinoma } \\
\hline & \multicolumn{2}{|c|}{ Ulcer (-) } & \multicolumn{2}{|c|}{ Ulcer (+) } & \multirow{2}{*}{$\begin{array}{c}\begin{array}{c}\mathrm{Sm} 1 \\
(\leq 500 \mu \mathrm{m})\end{array} \\
\leq 30 \mathrm{~mm}\end{array}$} & \multirow{2}{*}{$\begin{array}{c}\begin{array}{c}\text { Sm2 } \\
(>500 \mu \mathrm{m})\end{array} \\
\text { Any size }\end{array}$} \\
\hline & $\leq 20 \mathrm{~mm}$ & $>20 \mathrm{~mm}$ & $\leq 30 \mathrm{~mm}$ & $>30 \mathrm{~mm}$ & & \\
\hline Differentiated carcinoma & EMR & ESD & ESD & Surgery & ESD & Surgery \\
\hline Undifferentiated carcinoma & $\begin{array}{c}\text { ESD or Surgery } \\
\text { considered }\end{array}$ & Surgery & Surgery & Surgery & Surgery & Surgery \\
\hline
\end{tabular}

Table 1. Endoscopic indication for early gastric carcinoma

\subsection{Histologic evaluation of EMR/ESD specimens}

Proper handling EMR or ESD specimens is important to get an accurate histopathologic diagnosis. EMR or ESD specimens are evaluated carefully in slices at interval of $2 \mathrm{~mm}$ according to the recommendation by Japanese Classification of Gastric Carcinoma [70]. The risk stratification of lymph node metastasis in EMR or ESD requires careful and precise pathologic examination of the resected tissue. The location, size, gross appearance, histology, degree of differentiation, microscopic depth of tumor invasion, presence of ulceration, neoplastic involvement of the lateral and vertical margins, and involvement of the lymphatics and/or blood vessels in the submucosa must be reported in detail [82]. Invasion to the lateral margin of EMR or ESD specimens is classified into the following three groups based on endoscopic and histopathologic evidence: (1) Complete resection; when the lateral margin is clear endoscopically and pathologically (minimal probability of local recurrence); (2) Incomplete resection: when the tumor has definitely invaded the lateral margin endoscopically and pathologically (high probability of local recurrence); (3) Not evaluable: when the tumor has been removed endoscopically, but its lateral margin was not pathologically evaluable because of a burn effect (burned by diathermic treatment), or mechanical damage, or when reconstruction was difficult because of piecemeal resection [86]. The presence of submucosal invasion, positive vertical (deep) margin, and lymphovascular invasion (LVI) in the EMR or ESD specimens are indications for additional surgical intervention if any of these three histologic factors are present [87]. If only the lateral mucosal margin is positive as mapped out by the pathologists, a repeated ESD or ablative therapy of the involved area, may be attempted [88]. To date, large tumor size $(>3 \mathrm{~cm})$, the presence of LVI, and deep submucosal invasion $(>500 \mu \mathrm{m})$ are regarded as the most convincing indicators for a higher risk of lymph node metastasis in EGCs [89-91]. The recurrence rate of EGCs after EMR is highly variable, ranging from $2 \%$ to $35 \%$ in different studies, depending on the accomplishment of complete resection or not [92-95]. Every study agrees that EMR is associated with a higher risk of local recurrence compared to ESD due to the piecemeal resection of large lesions. Despite ESD has shown a higher frequency of enbloc and complete resections than EMR, the local recurrence rate of EGC after ESD still ranges from 1 to 5\% [96-98]. Therefore, surveillance biopsy from post- EMR sites is an important step in the follow up of patients to evaluate the residual or recurrent tumors. Mitsuhashi et al described pathologic features of 
the post-EMR biopsies which included, (1) architectural changes such as foveolar hyperplasia, villiform configuration, and lobular glandular proliferation; (2) cytologic changes such as increased mitoses ( $>2$ mitoses/foveola), epithelial cytologic atypia, anisonucleosis with or without microcystic configuration and flattened epithelia, clear cell degeneration, signet ring cell change, and mucin depletion; (3) stromal changes such as edema of the lamina propria, fibrinopurulent exudates and granulation tissue related to mucosal ulceration, acute and chronic inflammation, ecstatic blood vessels, ischemia, and hemorrhage [99]. Although most of mucosal changes seen in post-EMR biopsies seem to be benign, reactive and non-specific, among them, three pathologic features including lacy architectural change, clear cell differentiation, and signet ring cell-like change can create a diagnostic pitfall to pathologists, which should be distinguished from residual or recurrent adenocarcinoma based on the prior history of EMR and absence of nuclear atypia

\section{Advanced gastric carcinoma}

\subsection{Clinical manifestation}

Men are more frequently affected than women (male: female ratio; 2:1) and the median age at diagnosis is 70 years of age [3]. No specific physical signs or symptoms for gastric carcinoma exist. The common presenting symptoms and signs in advanced gastric cancer (AGC), however, include dysphagia, early satiety, epigastric pain, weight loss, anemia, anorexia, nausea, vomiting and melena. Dysphagia is frequently associated with proximal tumors, and early satiety can be caused by distal tumors or tumors with linitis plastica appearance due to gastric outlet obstruction or loss of stomach distensibility [100]. The symptom duration is less than 3 months in nearly $40 \%$ of patients and longer than 1 year in only $20 \%$ [101]. Presenting symptoms and signs in patients with distant metastasis of AGCs may be different from those with AGCs without distant metastasis. These patients may show enlarged abdominal mass or abdominal swelling due to tumor metastasis to the liver or malignant peritoneal effusion. Occasionally, the non-regional lymph node metastasis to the supraclavicular area can be superficial and palpable (Virchow's lymph node). Peritoneal metastatic spread may be evident as a palpable ovary on pelvic examination (Krukenberg tumor) or metastasis to the pouch of Douglas on rectal examination (Blumer's shelf sign) can be detected. Vaginal bleeding due to metastasis to the endometrium has been reported in premenopausal women with AGCs [102]. Patients with AGC may present with paraneoplastic syndromes such as diffuse seborrheic keratosis, acanthosis nigricans, microangiopathic hemolytic anemia, and Trousseau's syndrome [103]. The overall prognosis of AGCs is poor, with 5-year survival rate of $20 \%$ [104, 105]. Median survival for metastatic or unresectable disease is approximately 8 to 10 months [106].

\subsection{Methods for evaluation and staging}

An upper gastrointestinal tract radiography and endoscopy with biopsy have been used as gold standard tests for the detection of gastric cancer. Advantages of double-contrast upper 
gastrointestinal series are cost-effective, with a low risk of side effects and a high sensitivity ranging from $85 \%$ to $95 \%$ for the diagnosis of gastric carcinoma [107]. However, in some cases, the differentiation between a benign ulcer from a malignant one or gastric lymphoma can be challenging for radiologists in regard to subtle radiologic findings. Therefore, endoscopy with histologic confirmation has been a choice of procedure for evaluation of gastric cancer. The diagnostic accuracy rate of endoscopy with biopsy for upper gastrointestinal cancers is more than 95\% [104, 108]. The diagnostic accuracy of the biopsies usually increases with the increased numbers of sample taken. Many endoscopists generally take eight to ten biopsies and a minimum of six biopsies from any lesions is highly recommended with one from each quadrant and two from the center of the lesion [103]. Biopsy should be taken from the edge of an ulcerative lesion not from the base because when the biopsy is taken from the base of the ulcer, only necrotic tissue may be obtained. Gastric forcep biopsy may have limitation for the proper diagnosis and determination of degree of differentiation in some cases. Takao et al investigated the discrepancy rates of diagnoses between biopsy samples and resection specimens and found $1.4 \%$ of adenocarcinoma cases on resection specimens were under- diagnosed as either non-neoplastic lesions or adenomas in biopsies [109]. In regard to the discrepancy of the degree of differentiation, $97 \%$ of differentiated adenocarcinomas and $83 \%$ of undifferentiated adenocarcinoma in biopsies have concordant histology on resection specimens with a higher discordant rate in undifferentiated carcinoma cases in which undifferentiated component in biopsies may not represent the degree of differentiation in whole lesions. Therefore, they suggested endoscopic features should be considered together with the biopsy diagnosis to determine an appropriate treatment strategy for the lesions. Although a great effort has been made in search of specific markers that would enable for early detection of gastric carcinoma including CEA, CA19.9, CA72.4, CA50, and pepsinogen in the serum, and CEA, CA19.9, and fetal sulfoglycoprotein in the gastric juice [103, 110, 111], no specific biologic markers have been verified for specific gastric cancer markers. Once a diagnosis of gastric carcinoma has been made, endoscopic ultrasonography and computed tomography (CT) scan are usually employed for tumor staging. EUS is particularly useful to estimate the depth of tumor invasion for local staging. Accuracy of EUS for T staging in gastric carcinoma is approximately $82 \%$, with a sensitivity and specificity of $70 \%$ to $100 \%$ and $87 \%$ to $100 \%$, respectively [112-114]. However, differentiating T2 and T3 gastric carcinoma may be difficult in some cases due to associated fibrosis in T2 mimicking T3 lesions. Accuracy for $\mathrm{T}$ staging of gastric carcinoma by spiral CT is approximately $64 \%$, lower than that of EUS [115]. Detection of lymph node involvement by spiral CT scan is not reliable with sensitivity rates ranging from $24 \%$ to $43 \%$ [116], because lymph node size is not a good parameter for determining nodal metastasis. CT scan has been used for identifying distant metastasis to lung, liver, bone, etc. Magnetic Resonance Imaging (MRI) has been known to be almost comparable to CT scan for staging of AGC and useful to confirm a liver metastasis in equivocal cases [117, 118]. However, currently, MRI is limitedly used when the patients have an allergy to iodine contrast or renal failure due to motion induced artifacts, longer scanning times and higher cost than CT scan. 


\subsection{Gross features}

Approximately $50 \%$ of AGCs arise in the distal stomach (the pyloric part of the stomach), frequently involving the lesser curvature and 16\% of AGCs occur in the proximal stomach (cardia, the upper third of the body and fundus) [17]. AGCs may show various gross appearances with different growth patterns. For standardization of the common morphologic features of AGCs, several classification systems have been proposed. The most widely used classification for macroscopic appearance of AGC is Bormann classification, dividing AGCs into four types [119]:

Type 1 Polypoid: Well circumscribed polypoid tumors (Fig. 9).

Type 2 Fungating: Fungating tumors with marked central infiltration (Fig. 10).

Type 3 Ulcerated: Ulcerated tumors with infiltrative margins (Fig. 11).

Type 4 Infiltrating: Diffusely infiltrated tumors (Fig. 12).

In one large series, the percentage of each subtype was type 1 in $7 \%$; type 2 in $36 \%$; type 3 in $25 \%$; and type 4 in $26 \%$ [120]. The most common macroscopic type is a type 2 fungating tumor, which are frequently located in the lesser curvature of antrum. In contrast, polypoid (type 1) and ulcerated (type 3) types are commonly found in the greater curvature of corpus. On cut surface, AGC presents as a gray-white to yellow-white solid mass with a firm to hard consistency and contains areas of hemorrhage and necrosis.

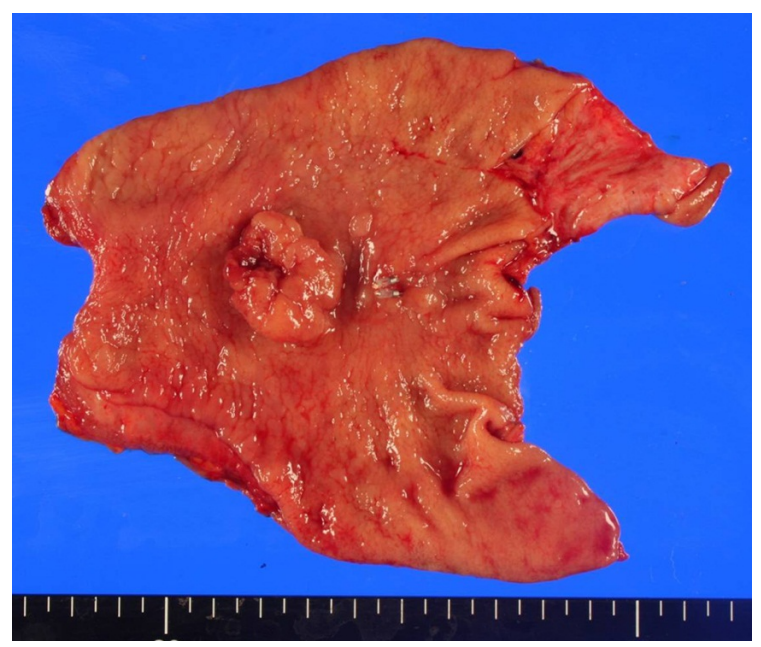

Figure 9. Bormann type 1. Polypoid carcinoma of the stomach is located in the antrum of the lesser curvature. This elevating solid mass shows focal superficial hemorrhage. 


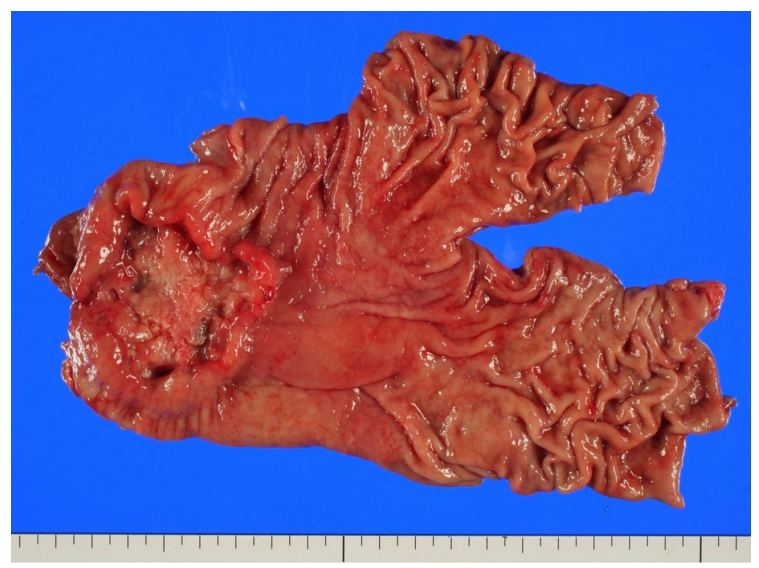

Figure 10. Bormann type 2. Fungating carcinoma of the stomach with extensive central ulceration involves the antrum.

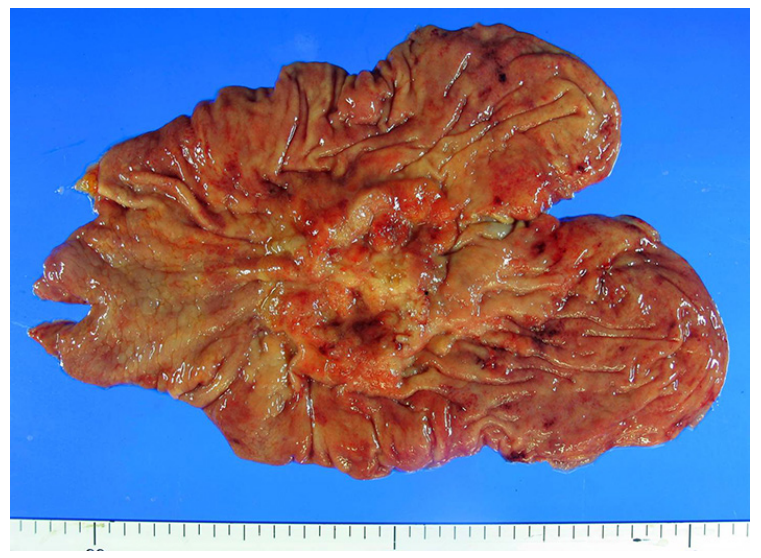

Figure 11. Bormann type 3. Ulcerated carcinoma of the stomach with infiltrative and heaped-up margins is present in the lower body of the lesser curvature. 


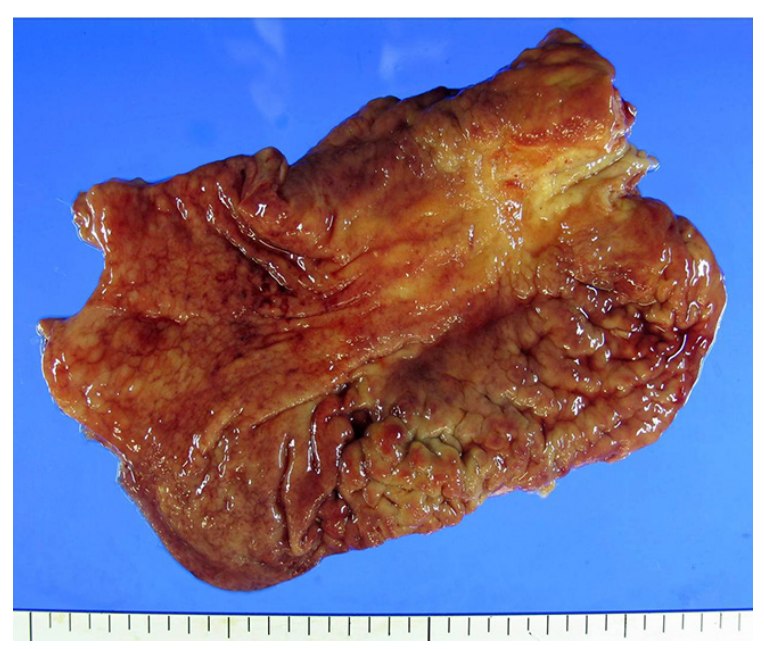

Figure 12. Bormann type 4. Linitis plastica, diffusely infiltrating carcinoma of the stomach with thickening of gastric rugae involves the whole stomach.

\subsection{Microscopic features and morphologic classifications}

Adenocarcinoma accounts for approximately 95\% of all malignant gastric neoplasms. Because of heterogeneity and complexity in the morphologic characteristics of gastric carcinoma, many histologic classification systems have been proposed. The primary histopathologic classification used for gastric carcinoma was first described in 1965 by Lauren [121]. This system provided a general understanding of histogenesis and biology of this disease. This classification simply divides gastric carcinomas morphologically into two types: diffuse and intestinal types, which have shown different genetic alterations and biologic behaviors. This classification has been applied to determine a clinical indication of endoscopic procedure or surgery and has supported unified epidemiologic data of gastric cancers by researchers.

Intestinal type adenocarcinoma usually arises in the older population with an increased incidence in men and is frequently associated with chronic atrophic gastritis, intestinal metaplasia and Helicobacter pylori infection in neighboring mucosa [122]. They constitute approximately $60 \%$ of gastric carcinoma in high-risk population and occur frequently in the antrum as exophytic bulky lesions [123]. These tumors have a tendency to spread hematogeneously and often result in liver metastasis. Helicobacter pylori infection, high-salt diet and smoking have been recognized as risk factors of intestinal type adenocarcinoma [6]. In regard to the carcinogenesis of intestinal type gastric carcinoma, Correa et al proposed a multistep progression from Helicobacter pylori infection and gastritis to intestinal type gastric carcinoma [124]. The sequence of changes in the stomach has been proposed that Helicobacter pylori infection or autoimmune gastritis causes atrophic gastritis with intestinal metaplasia, and transforms to dysplasia (adenoma) and further progress to adenocarcinoma. 
Multiple genetic alterations or mutations occur and accumulate in each step of carcinogenesis and result in malignant transformation. However, this hypothetical model only can apply to intestinal type adenocarcinoma but not to diffuse type. Microscopically, intestinal type adenocarcinomas show well developed glandular structures, either with papillary or tubular component, surrounded by a variable degree of desmoplastic stroma and a mixed inflammatory infiltration (Fig.13).

In contrast, diffuse type adenocarcinoma frequently occurs in younger patients, with equal distribution among men and women [122]. It tends to spread by direct tumor extension, resulting in peritoneal metastasis. Diffuse type adenocarcinoma has been believed to derive de novo from the peripheral stem cells of gastric gland neck proliferation zone without a recognizable precursor lesion $[125,126]$. Grossly, this tumor frequently shows ulcerations and occasionally combines with rigid, thickened, leather-bottle appearance of the gastric wall, called linitis plastica. Microscopically, diffuse type adenocarcinoma is composed of individual tumor cells with or without signet ring cell configuration or small clusters of discohesive pleomorphic cells with little or no gland formation, which commonly deeply invade the full thickness layers of the gastric wall with desmoplastic reaction. Different clinicopathologic features of intestinal and diffuse type gastric carcinomas are listed in table 2.

Diffuse gastric cancer rarely can be hereditary with an autosomal dominant disorder which accounts for less than $1 \%$ of all cases of gastric carcinoma [6]. This disease is caused by germline mutation of CDH1 gene that encodes the cell adhesion protein Ecadherin, which plays an essential role in maintenance of the epithelial glandular structure [127]. Diffuse gastric carcinoma is the main cause of cancer mortality in patients with CDH1 gene mutation [128].

\begin{tabular}{lcc}
\hline Age & Intestinal adenocarcinoma & Diffuse adenocarcinoma \\
\hline Sex & Old age & Young age \\
\hline Risk factors & M > F & M F F \\
\hline Precursors & $\begin{array}{l}\text { Helicobacter pylori infection, } \\
\text { high salt diet, and smoking }\end{array}$ & CDH1 gene mutation \\
\hline Surrounding gastric mucosa & Adenoma or dysplasia & Tubule-neck dysplasia or \\
\hline Common location & Atrophic gastritis with & signet ring cell carcinoma in situ \\
\hline Gross feature & Antrum and angulus & $\begin{array}{c}\text { Non-atrophic gastritis or } \\
\text { nonmetaplastic mucosa }\end{array}$ \\
\hline Microscopy & Exophytic lesion & Corpus and whole stomach \\
\hline Routes of cancer dissemination & Hematogenous spread & Direct invasion into the surrounding organs \\
\hline
\end{tabular}

Table 2. Clinicopathologic features of intestinal and diffuse types of gastric adenocarcinomas 
Some AGCs may not fit into one of two types clearly, and thus fall into mixed or unclassified categories. Mixed type gastric carcinoma accounts for approximately $14 \%$ of all gastric carcinoma [121, 129, 130]. However, there have been only a few studies investigating the clinicopathologic features of mixed type AGCs. In recent series by Zheng et al, mixed type adenocarcinomas exhibit larger size, deeper invasion, more frequent local invasion, and lymph node metastasis compared to intestinal or diffuse type gastric carcinomas [131]. Kozuki et al also demonstrated a similar result; prominent lymphatic permeation and lymph node metastasis were more frequently observed in mixed type than the pure type of gastric carcinoma [132]. These findings suggest that mixed type adenocarcinoma of the stomach may have more aggressive behavior than two pure types and could be separated as a distinct entity.

In 1977, Ming proposed another classification system of gastric carcinoma based on the pattern of tumor growth and invasiveness as an indicator of biological behavior, expanding vs. infiltrative type [133]. The expanding type adenocarcinomas grow predominantly by expansion with a sharply delineated periphery, resulting in a nodular growth of tumor. In contrast, the infiltrative type tumors show diffuse infiltration of tumor cells into the layers of gastric wall, without forming masses or nodules. There are some overlapping features between Lauren and Ming classifications. In most of cases, expanding types of AGC by Ming's classification are classified as intestinal types and infiltrative adenocarcinomas are diffuse types. However, Ming's classification was made based on the predominant tumor growth pattern, which limits its value to gastrectomy specimen and cannot be applied to biopsy specimens [134].

In 1992, Goseki et al proposed a classification system of AGC based on the degree of tubular differentiation and the amount of intracellular mucin production [135]. This system divides AGCs into four groups based on tubular differentiation and mucin production by tumor cells. Four grades of tumor were proposed: group I: well differentiated tubules, intracellular mucin poor; group II: well differentiated tubules, intracellular mucin rich; group III: poorly differentiated tubules, intracellular mucin poor; group IV: poorly differentiated tubules, intracellular mucin rich. The prognostic value of Goseki's classification has been investigated in only a few studies in patients with AGCs and its prognostic value remains controversial [136-140 ].

Although the Lauren and other classifications provide a simplified categorization of usual gastric carcinomas and better understanding of their biology and behavior in large epidemiologic studies, they are less useful to apply to a variety of histologic subtypes of gastric carcinoma for predicting their clinical outcome. World Health Organization (WHO) proposed a classification to meet this need based on traditional histopathologic features and the degree of differentiation of gastric carcinoma [141]. Gastric adenocarcinomas are graded like other glandular neoplasms based on the degree of glandular differentiation into well, moderately, and poorly differentiated subtypes. Well differentiated carcinoma consists predominantly of recognizable, well-formed glands with greater than $95 \%$ of glandular component in a tumor. Poorly differentiated tumors have a little gland formation consisting of pleomorphic tumor cells arranged in solid sheets or clusters with less than $50 \%$ of gland formation in 
a tumor. Moderately differentiated tumors are intermediate with 50-95\% of gland formation in a tumor. The degree of differentiation is considered as an important prognostic factor that is highly associated with the depth of tumor invasion and a risk of lymph node metastasis [142-144]. WHO classification has been also used for determining the therapeutic options of patients with gastric carcinoma. The degree of differentiation is one of the important criteria for performing endoscopic resection.

In WHO classification, gastric carcinomas are divided into five categories based on histopathologic features including adenocarcinoma, adenosquamous carcinoma, squamous cell carcinoma, undifferentiated carcinoma, and unclassified carcinoma [145]. Adenocarcinomas are subdivided into papillary, tubular, mucinous and signet ring cell types. Generally, papillary and tubular variant are classified into intestinal, expanding, or differentiated type, whereas, mucinous and signet ring cell variants are categorized into diffuse, infiltrative, or undifferentiated type [146].

Tubular adenocarcinoma consists of tubular-shaped branching glands lined by pseudostratified columnar or cuboidal epithelium with elongated hyperchromatic nuclei having coarse chromatin and occasional mitotic figures (Fig. 14). Acinar structure may be present. The degree of cytologic atypia varies from low grade to high grade tumors. If tubular adenocarcinoma combines with papillary adenocarcinoma component, it is termed as a tubulopapillary variant.
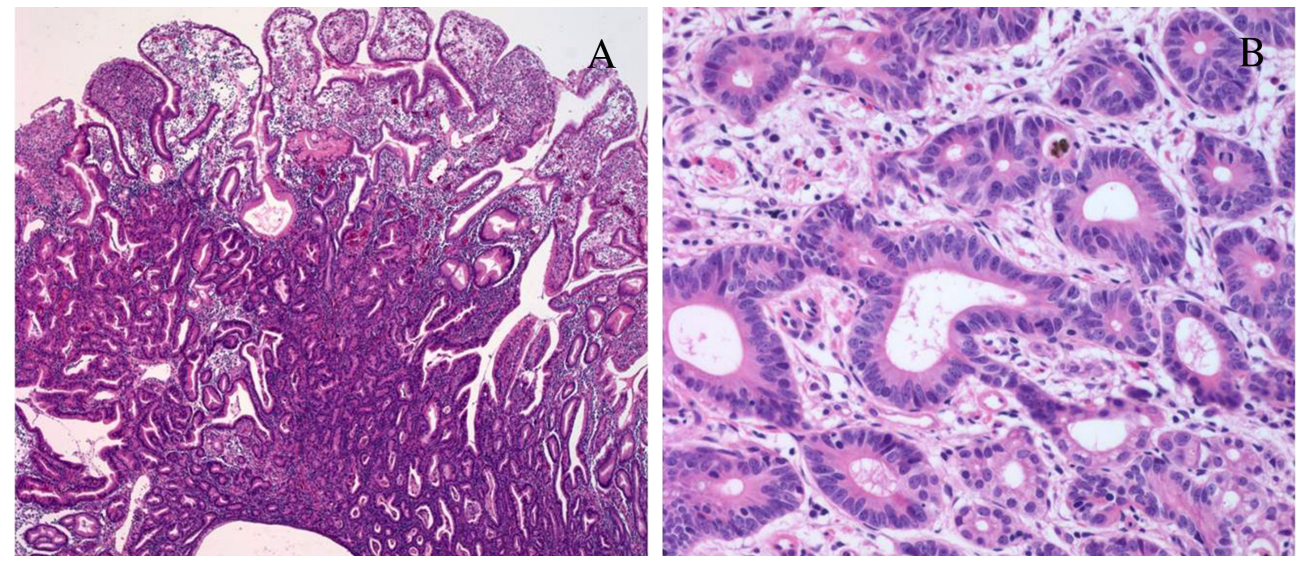

Figure 13. A. Gastric biopsy shows a well differentiated tubular adenocarcinoma. Adjacent to the carcinoma, regenerative foveolar epitheliums are admixed. B. In high power examination, the anastomosing glands are composed of atypical cells with vesicular nuclei and prominent nucleoli. 

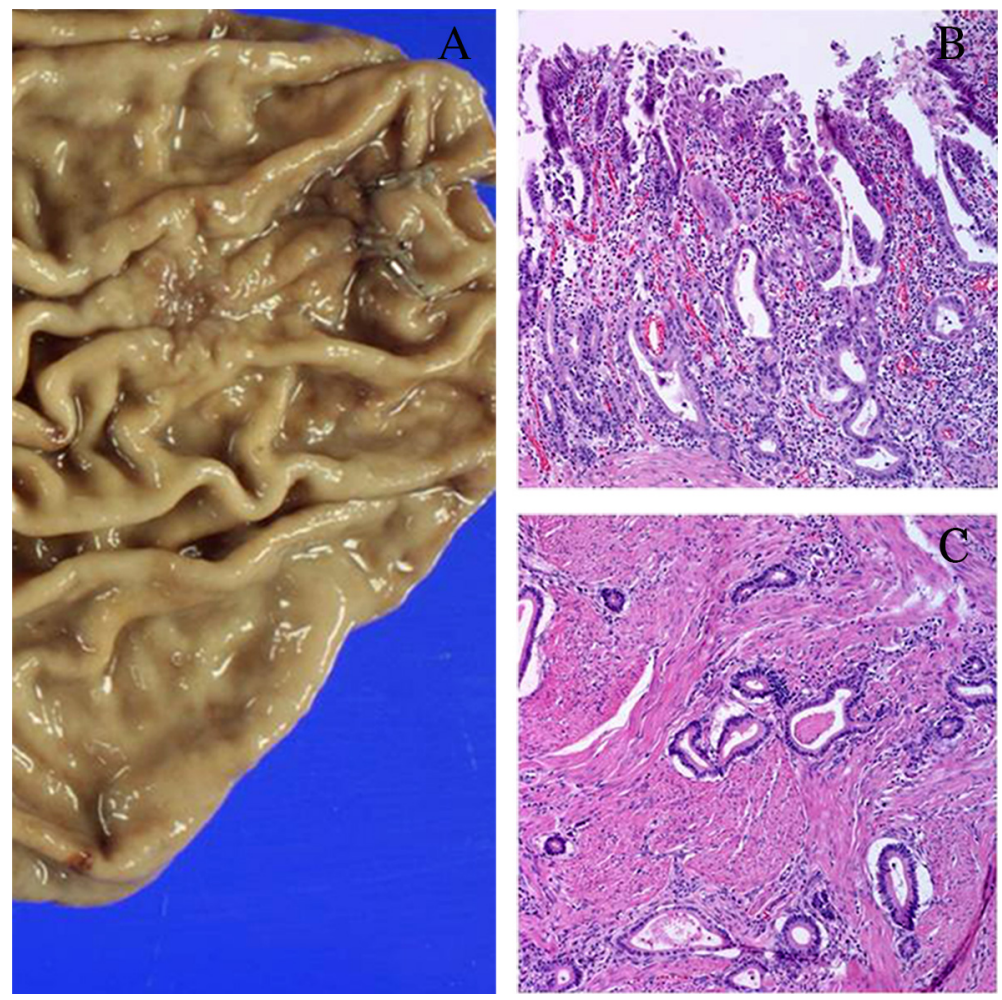

Figure 14. Tubular adenocarcinoma, well differentiated, in the resected stomach. A. Grossly, the tumor in the high body of greater curvature is advanced gastric carcinoma mimicking EGC type IIb. B. In the superficial area, the carcinoma mimics regenerative changes due to its bland morphology. C. However, the carcinoma infiltrates into subserosa.

Papillary adenocarcinoma is characterized by elongated finger-like processes that have a fibrovascular connective tissue core in the center and lined by cylindrical or cuboidal cells. The nuclear cytologic atypia varies from low to high grade. This tumor represents $6 \%$ to $11 \%$ of all gastric carcinomas $[68,147]$. Papillary adenocarcinomas have distinct clinicopathologic features such as a higher frequency in aged patients, proximal location, and elevated macroscopic type [147]. Although papillary adenocarcinoma has been categorized into differentiated-type adenocarcinoma with low grade malignancy, some studies have shown that papillary adenocarcinomas of the stomach have a higher frequency of lymph node metastasis, liver metastasis and poorer surgical outcome compared to other types of gastric carcinoma [147-149]. Nakashima et al proposed a nuclear grading score for papillary adenocarcinoma of the stomach based on the extent of nuclear pleomorphism and nuclear polarity 
[150]. They also reported that papillary adenocarcinoma with a high nuclear grade is usually accompanied by more advanced mural invasion, a higher risk of lymph node metastasis, higher chances of HER2 overexpression, and poorer prognosis. This study suggested that papillary adenocarcinomas with high nuclear grade of the stomach may be a good therapeutic candidate for anti-HER2 (trastuzumab) therapy.

Mucinous adenocarcinomas are also referred to as colloid, mucous, and muconodular carcinoma. This tumor accounts for $2 \%$ to $6 \%$ of all gastric carcinomas [151]. Mucinous adenocarcinoma is defined as a gastric adenocarcinoma with a substantial amount of extracellular mucin ( $\geq 50 \%$ of tumor volume) within tumors [145]. They may present in one of two forms; tubular glands with mucus-secreting epithelium surrounding collections of extracellular mucin and signet ring cells floating in the mucinous lake [152]. Sometimes, the tumor is predominantly composed of large acellular mucin pools with a few scattered tubular glands or signet ring cells (Fig. 15). The clinical outcome and prognosis of mucinous adenocarcinoma compared to non-mucinous adenocarcinoma is controversial. Some authors reported that the prognosis of patients with mucinous adenocarcinoma is poorer than that of patients with non-mucinous adenocarcinoma [153]. However, others demonstrated that the 5-year survival rates of mucinous and non-mucinous adenocarcinomas are not different when the tumors are compared stage by stage [152]. A recent study from South Korea reported that in mucinous gastric carcinomas, tumor size predicted prognosis more accurately than conventional pT stage (depth of invasion in a study with large number of cases) [154].

Signet ring cell adenocarcinoma of the stomach is characterized by diffuse infiltration of signet-ring type of tumor cells into the gastric wall. It accounts for $18 \%$ of total gastric carcinomas and $13.9 \%$ of all AGCs [155]. Histologically, signet ring cell carcinoma is defined as an adenocarcinoma in which the predominant component (more than $50 \%$ of the tumor) consists of isolated or small groups of malignant cells containing intracytoplasmic mucin with eccentric nuclei (Fig. 16) [145]. Most signet ring cell carcinomas accompany with marked desmoplasia within tumor. Signet ring cell carcinomas diffusely infiltrate through the muscular propria and subserosa with sparing the mucosa and present as firm and non-distensible texture, forming leather bottle appearance of stomach (linitis plastica). In these cases, because a few scattered tumor cells are embedded in the desmoplastic stroma, it is easy to overlook the presence of malignant cells. Therefore, a careful pathologic examination is strongly recommended for delineating free margins and depth of tumor invasion during evaluation for frozen sections as well as permanent sections of gastrectomy specimens. In problem cases, mucin stains (periodic acid-Schiff, Alcian blue, mucicarmine) and immunohistochemical staining for cytokeratin would be greatly helpful to demonstrate tumor cells. Li et al reported that the mean tumor size and depth of invasion of signet ring cell carcinoma is slightly larger and deeper than those of non-signet ring cell carcinoma [155]. This tumor is frequently discovered at an advanced stage such as, stage IIIb and IV, and shows a higher rate of lymph node metastasis and peritoneal dissemination [155, 156], and is associated with the poorer prognosis than other types of adenocarcinoma. 


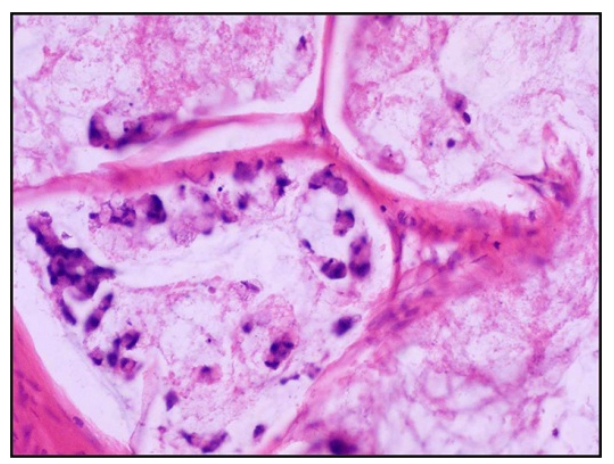

Figure 15. Mucinous carcinoma. Small clusters or strands of pleomorphic tumor cells containing mucin are present within mucin pool.

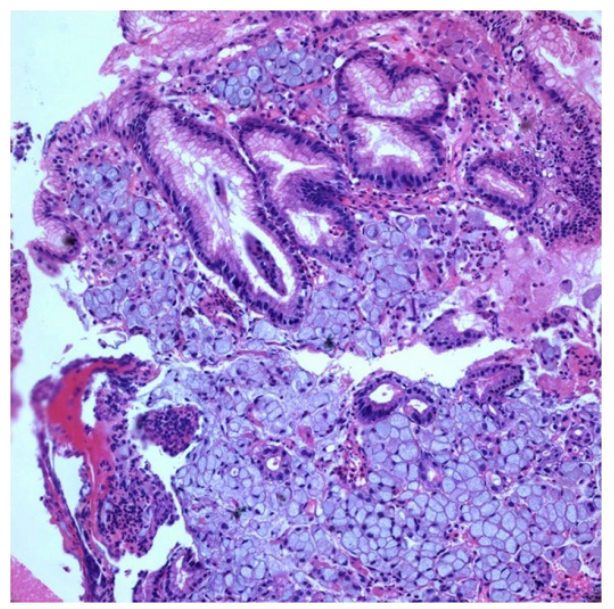

Figure 16. Signet ring cell carcinoma. Signet ring cells showing foamy or pale basophilic abundant cytoplasm and an eccentrically located nucleus infiltrate the lamina propria.

\subsection{Immunohistochemistry}

Gastric carcinomas have various amounts of differentiated tumor cells that may express heterogeneous phenotypes of mucin. Mucins are high molecular weight glycoproteins with complexity and diversity that constitute the major component of the mucus layer within the gastric epithelium. Up to date, twelve core proteins of human mucin have been described. It has known that normal human stomach can express MUC1, MUC5AC, and MUC6. MUC1 and MUC5AC are expressed in the superficial foveolar epithelium and mucous neck cells of both the antrum and corpus, whereas MUC6 is expressed in the pyloric glands of antrum and the mucous cells of the neck zone of the corpus [157-160]. In contrast, MUC2 is found in 
the Golgi region of foveolar cells in the antrum and predominantly express in the areas of intestinal metaplasia with vacuolar staining in goblet cells [161, 162]. MUC5B is expressed only during a brief period of fetal life [163]. Previous studies have shown that MUC5AC expression in gastric carcinoma is associated with diffuse type gastric carcinoma and EGC $[164,165]$. The expression of MUC2 is closely correlated with mucinous carcinoma and cardia adenocarcinoma [164]. In additional studies by Pinto-de-Sousa et al, MUC5B was aberrantly expressed in $22 \%$ of gastric carcinomas and is associated with differentiation and coexpression of MUC5AC [166]. Expression of MUC1 is less frequent in adenoma compared to associated carcinoma [167]. In contrast, MUC2, an intestinal type mucin, was highly expressed in the adenomas, but either persisted or decreased after malignant transformation to adenocarcinomas. These findings suggest that MUC2 expression would be an early event, while MUC1 expression would be a late event in the carcinogenesis of the stomach [159]. The pattern of mucin expression may help to understand the differentiation pathway of gastric carcinoma and to predict its biologic behavior. However, it is still controversial whether expressions of mucin in gastric carcinoma have a prognostic significance or not.

Immunohistochemical staining of cytokeratin 7 and cytokeratin 20 show various expression in the stomach. Cytokeratin 20 is usually positive for antral epithelium, while cytokeratin 7 highlights the columnar cells of the cardia. It has known that adenocarcinomas of GEJ are more likely expressed CK7 and distal gastric adenocarcinoma are likely express CK20 [168].

\section{Molecular pathology of gastric cancer}

Although the carcinogenesis of gastric carcinoma is not clear, a rapid progress in the molecular biology of cancer helps us to understand a complex process of malignant transformation of the gastric epithelium caused by the accumulation of aberrant genetic mutations. Gastric cancer is a heterogeneous disease with multiple environmental etiologies and alternative pathways of carcinogenesis. Beyond mutations in TP53, alterations in other genes or pathways account for only small subsets of the disease [169]. Recent studies using next-generation sequencing (NGS) have revealed an extensive repertoire of potential cancer-deriving genes in several cancer types. In stomach, recent exome sequencing data with 22 AGCs showed that genes involved in chromatin modification to be commonly mutated. A downstream validation study confirmed frequent inactivating mutations or protein deficiency of ARID1A, which encodes a member of the SWI-SNF chromatin remodeling family, in $83 \%$ of gastric cancers with microsatellite instability (MSI), 73\% of those with Epstein-Barr virus (EBV) infection and $11 \%$ of those that were not infected with EBV and microsatellite stable (MSS). Subsequent exome sequencing data with 15 AGCs showed similar genetic alterations; frequently mutated genes in the adenocarcinomas included TP53 (73\%), PIK3CA (20\%), and ARID1A (20\%), and suggested that FAT4 and ARID1A may thus be key tumorigenetic events in subset of gastric cancers [170]. In a search for COSMIC (Catalogue Of Somatic Mutations in Cancer) data, TP53 mutations is the most frequent mutation followed by CDH1, ARID1A, MSH6, PIK2CA, CDK2A, APC, FBXW7, KRAS, CTNNB1, PTEN,EGFR, ERBB2, HRAS and BRAF (Fig.17). Recent high throughput mutation profiling showed simi- 
lar results [171, 172]. Lee et al first described that mutations of CTNNB1 were significantly more frequent in EBV-associated gastric carcinoma [171].

Molecular targeted therapies have significantly emerged as an effective treatment and improved clinical outcomes of many common malignancies, including breast, colorectal, and lung cancers. Although studies for targeting agents of gastric cancer did not show promising results in the past decades, recently, trastuzumab has been approved by US Food and Drug Administration (FDA) and European Medicine Agency as a first-line therapy in $\mathrm{Hu}^{-}$ man epidermal growth factor receptor (HER) 2 positive metastatic gastric cancers and GEJ cancers based on the result of a landmark clinical trial, so called ToGA (Trastuzumab for Gastric Cancer) study. Currently, many other molecular targeted agents for AGCs are undergoing clinical trials, including vascular epithelial growth factor (VEGF) inhibitor, other HER family targeted agents, and etc. In this chapter, we focus on two main targeting agents, HER2 and VEGF inhibitors, and discuss about their biologic pathways and the results of clinical trials.

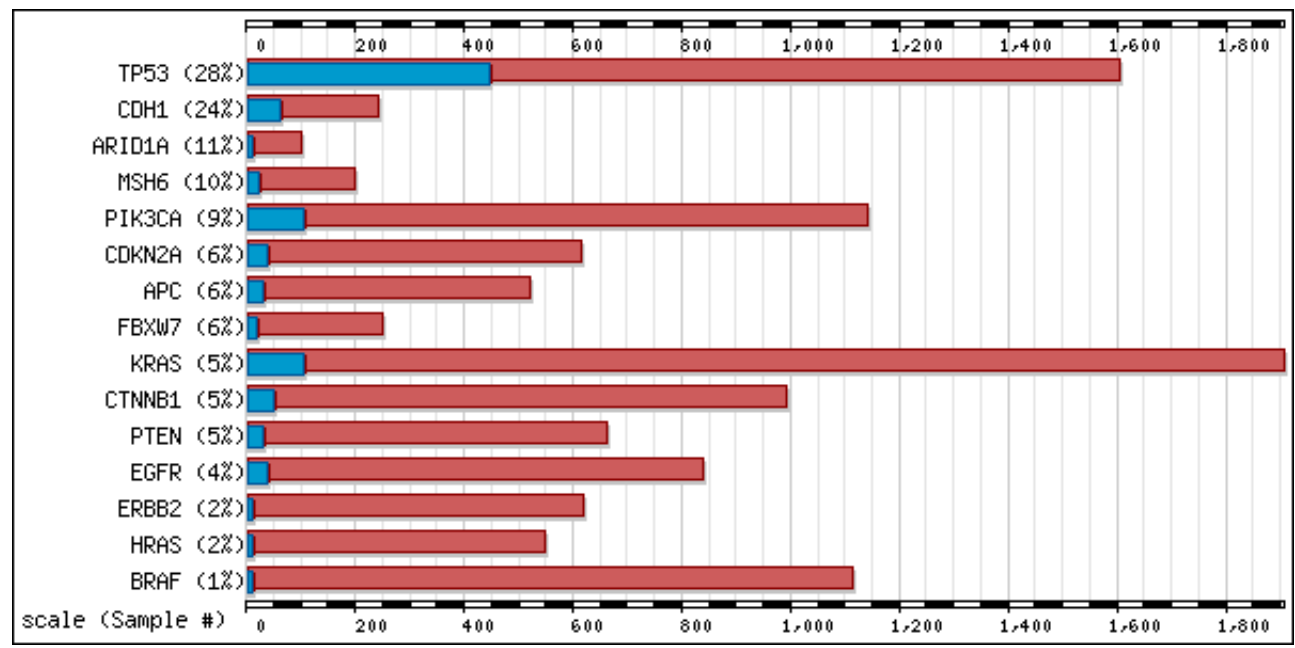

Figure 17. The graph highlights the most significantly mutated genes of gastric cancer from the Cancer Gene Census. Source: COSMIC: a open information showing somatic mutation related with human cancer, Sanger Institute. http:// www.sanger.ac.uk/genetics/CGP/cosmic/

\subsection{Next-generation sequencing of gastric cancer}

Recent genome-wide sequencing studies demonstrated that mutations of AT-rich interactive domain 1A gene (ARIDI1A) were identified in 8-11 \% of gastric cancer and frequently in EBV-positive gastric cancer and MSI-high gastric cancers [170, 173, 174]. ARIDI1A is one of the subunits of the Switch/Sucrase Non-fermentable (SWI/SNF) chromatin remodeling complex and involves the regulation of gene expression by binding to AT-rich DNA sequences [175]. ARIDI1A seems to act like a tumor suppressor gene that involves DNA repair, differ- 
entiation, development, and has a regulatory role in proliferation [175, 176]. ARIDI1A gene mutation has been reported in ovarian cancer, predominantly clear and endometrioid subtypes, and its rearrangement or deletion were identified in breast and lung cancer cell lines [176-178]. Recently, Wang et al demonstrated that gastric cancers with ARIDI1A mutation and loss are a distinct molecular subtype affecting predominantly EBV-positive and MSIhigh gastric cancers, with a better prognosis and different carcinogenesis compared to the conventional gastric adenocarcinoma. They also demonstrated that ARIDI1A mutations are reversely associated with mutations of TP53 but concur with PIK3CA mutations. In large retrospective series by Abe et al, loss of ARIDI1A correlates with larger tumor size, advanced invasion depth, lymph node metastasis, and poor prognosis in EBV negative and MSS gastric cancers [174]. They also suggested that loss of ARIDI1A in EBV-positive gastric cancer is an early event in carcinogenesis and may precede EBV infection in gastric epithelial cells.

\subsection{Activation of oncogenes}

The MET proto-oncogene encodes a tyrosine kinase receptor for the hepatocyte growth factor and stimulates mitogenesis, motogenesis, vasculogenesis, and morphogenesis of the cells [179]. Its overexpression was found in $20 \%$ of diffuse and $40 \%$ of intestinal type gastric carcinomas. [180-182]. In series of MET gene activation, tumors with c-met protein tended to display increased invasiveness and poorly differentiated histology with poor prognosis on multivariate analysis [183, 184].

Fibroblast growth factor receptors (FGFRs) consist of four different variants and their overexpressions are associated with a poorer prognosis in patients with gastric carcinoma [185, 186]. FGFR type II encoding a receptor for keratinocyte growth factor is overexpressed in $33 \%$ of diffuse type of AGCs but not in intestinal type carcinomas [186, 187].

Another proto-oncogene, epidermal growth factor receptor genes including HER2 is overexpressed in $20 \%$ of intestinal type AGCs but not in diffuse type carcinomas [188]. More detailed description of ERBB2 is in the next section.

\subsection{Inactivation of tumor suppressor genes}

The TP53 gene located at 17p13.1 encodes a nuclear protein, which involves cell cycle control, DNA repair, cell differentiation and programmed cell death [181]. Mutation or loss of heterozygosity $(\mathrm{LOH})$ of the TP53 gene has frequently been demonstrated in gastric adenocarcinoma. $\mathrm{LOH}$ occurs in $64 \%$ and mutations in approximately $30-50 \%$ of gastric carcinomas [189]. Most alterations of the TP53 gene occur in AGCs. In intestinal type gastric carcinomas, although p53 gene mutations have been identified in 50\% of EGCs and seem to be an early event, there was no proven relationship with tumor stage or progression [190, 191]. However, in diffuse type gastric carcinomas, TP53 gene mutations are significantly increased in advance stage, indicating the importance of TP53 mutations for tumor stage progression. 
Deletions or mutations of the adenomatous polyposis coli (APC) gene located on chromosome 5 q21 have been detected in up to one third of gastric carcinoma cases [192]. LOH of the APC gene occur in approximately $20 \%$ of intestinal type gastric carcinomas but not in diffuse type [193]. However, the frequency of APC gene mutations by histological types has been controversial and the role of APC gene in the carcinogenesis of gastric carcinoma is not clear yet compared to colorectal counterpart.

RUNX3 is a recently discovered tumor suppressor gene that is involved in gastric carcinogenesis. RUNX3 plays an important role for the suppression of cell proliferation in the gastric epithelium by inducing p21 expression in cooperation with TGF- $\beta$ activated SMAD [194]. Loss of RUNX3 by hypermethylation of the promoter CpG island is observed in $45-65 \%$ of gastric carcinomas $[195,196]$.

Phosphatase and tensin homologue (PTEN) is located on chromosome 10q23.3 and acts as a plasma membrane lipid phosphatase. PTEN dephosphorylates the second messenger phosphatidylinositol-3,4,5-triphosphate, the product of phosphatidylinositol-3-kinase [197]. PTEN opposes the downstream signaling of phosphatidylinositol-3-kinase/ATP dependent tyrosine kinase pathway (PI3K) which involves the regulation of apoptosis, cell proliferation, migration, angiogenesis, and glucose metabolism [198]. Mina et al reported that PTEN deletion was found in 8 of 180 gastric cancer cases (4.4\%) by fluorescence in-situ hybridization (FISH) and correlated with a higher rate of lymph node metastasis and distant metastasis indicating an aggressive behavior, which is similar to previous studies [199-201]. Interestingly, Esteva et al reported that PTEN loss in patients with HER2 positive metastatic breast cancer was significantly associated with a poor response to trastuzumab therapy and a shorter survival time, suggesting its pivotal role in trastuzumab resistance [202].

\subsection{Cell-adhesion molecules and metastasis-related gene}

The Wnt signaling pathway plays an essential role in embryonic development and a variety of processes including cell cycle regulation in differentiated cells. The Wnt signaling pathway also includes the regulation of $\beta$-catenin, which has multiple cellular functions, from cell surface signaling involving E-cadherin to nuclear translocation [106]. Mutations in the genes encoding Wnt pathway components are associated with various malignancies including tumors of gastrointestinal tract, in particular gastric cancer. E-cadherin, one of the members of the cadherins, acts as an adhesive molecule and plays an important role in growth development and carcinogenesis. E-cadherin gene located at chromosome 16q22 can be inactivated by mutation, $\mathrm{LOH}$, and hypermethylation [181]. Because E-cadherin is a components of adhering junctions, the mutations of E-cadherin and related genes result in the dyscohesiveness of tumor cells in the morphology of diffuse type adenocarcinoma. Decreased expression of E-cadherin is predominantly found in undifferentiated, diffuse type gastric carcinomas, particularly in signet ring cell carcinoma and associated with invasiveness and a higher metastatic potential of gastric carcinomas resulting in a poorer prognosis [203, 204]. Hereditary diffuse gastric cancer is caused by germline mutations of E-cadherin (CDH1) [205]. Hypermethylation of E-cadherin promoter is another alternative pathway to inactivate E-cadherin gene and found in $83 \%$ of cas- 
es with sporadic diffuse type gastric carcinoma [206]. The Wnt signaling pathway would be less implicated for malignant transformation of intestinal type adenocarcinoma than diffuse type. APC gene mutations and mutations in the exon 3 of $\beta$-catenin lead to decreased phosphorylation of $\beta$-catenin and reduced proteolytic degradation of this protein in the Wnt pathway, which result in cytosolic accumulation of $\beta$-catenin, its nuclear translocation, and following malignant transformation of the gastric epithelium into intestinal type gastric carcinoma [207, 208].

\subsection{Epigenetic alteration}

Aberrant methylation of promoters may lead to the transcriptional silencing of various genes including E-cadherin, p16, p15, MGMT, CDKN2A, RUNX3 and MLH1. It has been reported that $40 \%$ of gastric carcinomas have CpG island methylation with frequent methylation in p16 and MLH1 genes [209]. CpG islands are DNA segments that are at least $0.5 \mathrm{~kb}$ in size, rich in G:C and CpG content, and found in approximately $70 \%$ of human gene promoters as an unmethylated status [210]. Promotor CpG island hypermethylation is found in almost all cancers and involves in carcinogenesis and aging process by affecting on the tumor related genes and the inactivation of tumor suppressor genes. Kang et al suggested that promotor CpG island hypermethylation occurs in an early step of the gastric carcinogenesis and accumulate during malignant transformation [211].

MSI is a DNA mismatch repair deficiency that is one of the pathways of gastric carcinogenesis. MSI has been found in 13\%-44\% of sporadic gastric carcinomas [212-214]. In gastric carcinomas, MSI is mainly caused by promoter CpG island hypermethylation of MLH1 gene $[215,216]$. MSI due to epigenetic inactivation of MLH1 is found in 15\%-39\% of sporadic intestinal type carcinomas, $70 \%$ of which are associated with loss of MLH1 by hypermethylation of the promoter [215, 217]. Gastric carcinomas can be classified as MSI-low and MSIhigh depending on the degree of genomic instability. MSI-high gastric carcinomas have some distinct clinicopathologic characteristic such as an association with intestinal type, distal stomach (antrum), and more favorable prognosis compared to MSS and MSI-low carcinomas [218]. In addition, some studies have shown that MSI-high gastric carcinomas have a lower risk of lymph node metastasis, near-diploid DNA content and tumoral lymphoid infiltration [219-221]. It is controversial that MSI involves in the early or late stage of gastric carcinogenesis due to contrary data. Particularly, EBV-positive gastric carcinoma is well known for global and nonrandom CpG island methylation of the promoter regions of cancer-related genes. Previous studies demonstrated that EBV-positive gastric carcinomas were strongly associated with CpG-island methylator phenotype and having multiple methylation of cancer related genes including genes of DNA repair and protection (MLH1, MGMT, and GSTP1), cell cycle regulation (p14,15,16, and cox2), cell adherence and metastasis (Ecadherin, bcl-2, and p73)[222-225]. However, the relationship between EBV-positive gastric cancer and MSI is not clear because some studies reported that EBV-positive gastric carcinomas presented with MSI-high but others showed no MSI in EBV-positive gastric carcinomas [212, 226-228]. Recently, Park et al reported that in multiple gastric carcinomas, EBV infec- 
tion allows the gastric mucosa to escape from aberrant methylation of MLH1 and induces a malignant pathway independent of MSI [229].

Human telomerase reverse transcriptase (hTERT) is an important determinant of telomerase activity, the enzyme that catalyses the telomere DNA synthesis [230]. It has been reported that the majority of intestinal type gastric carcinomas have shortened telomere length, high levels of telomerase activity and a significant expression of hTERT [231, 232].

\subsection{Molecular targeted therapies and related molecular changes}

Therapeutic response and prognosis may be highly variable in patients with AGC within the same stage and chemotherapy regimens. Considering cancer is a product of accumulated genetic aberrations, elucidation of complex biological mechanism of cancer results in developing new molecular markers that would be specific for only tumor cells. Molecules that are closely associated with cell proliferation, invasion, and metastasis have been studied as potential candidates for targeted therapy. In gastric and GEJ carcinomas, some candidate molecules for targeted therapy such as epidermal growth factor (EGFR), vascular endothelial growth factor (VEGF), and P13K/AKT/mTOR pathway, as well as insulin-like growth factor receptor (IGFR), MET pathways, and FGFR have been actively investigated [179]. Two molecular target agents approached to phase III clinical trial are EGFR and VEGF inhibitors.

HER2 (c-erbB2) protooncogene is located on chromosome 17q11.2-12 and encodes a tyrosine kinase receptor that is overexpressed in several types of cancer, including gastric and breast cancers [233]. The HER family proteins regulate cell growth, survival, adhesion, migration, and differentiation, which can be amplified or weakened in tumor cells. It has been reported that HER2 gene amplification and/or protein overexpression in $13 \%$ to $23 \%$ of gastric and GEJ carcinoma [234-237]. HER2 overexpression is strongly associated with poor clinical outcome and disease aggressiveness [238-241]. Recently, the ToGA trial which compared trastuzumab plus chemotherapy vs. chemotherapy alone in patients with HER2-positive AGCs, mostly AGCs and GEJ cancers, [234] demonstrated that adding trastuzumab to the conventional chemotherapy is therapeutically superior in patients with HER2- positive AGCs than chemotherapy alone group.

Lapatinib is another HER2 targeted agent which is a dual tyrosine kinase inhibitor of EGFR and HER2. It has been actively investigated as a candidate agent for patients with trastuzumab-resistant gastric and GEJ cancers [242].

VEGF is a signal protein produced by cells that plays a key role in angiogenesis within a tumor and increases microvascular permeability [243]. It has been well known that tumors cannot grow beyond a certain limited size if it does not have an adequate blood supply. Tumors produce and secret VEGF and related receptors to enhance neovascularization. Increased expression of VEGF has been found in approximately $43 \%$ of gastric cancers and is associated with advanced stage, a higher risk of recurrence, and poor prognosis [244]. Karayiannakis et al reported that the serum VEGF concentration is strongly associated with metastasis and poor prognosis in patients of gastric and GEJ carcinomas [245]. These data have shown that VEGF would be a good molecular marker 
which can be detected not only from tumor tissue but also from serum. The recently introduced and evaluated anti-VEGF therapy are composed of the monoclonal antibody, bevacizumab, and multitargeted tyrosine kinase inhibitors, sunitinib and sorafenib [242]. Bevacizumab is a combinant humanized monoclonal antibody that targets VEGF. Previous studies have shown that a combination therapy with bevacizumab and chemotherapy significantly enhances the efficacy of chemotherapy in colorectal, lung, and renal cell carcinoma as well as recurrent glioblastoma [246-249]. The first phase III study of bevacizumab (generic name, avastin), the Avastin in Gastric Cancer (AVAGAST) trial, was to evaluate the therapeutic efficacy of bevacizumab combined with chemotherapy (capecitabine plus cisplatin) vs. chemotherapy alone as a first line therapy in patients with unresectable AGCs [250]. Although AVAGAST trial did not get a satisfying result with no significant difference in overall survival, however, both progression-free survival and overall response rate were improved in some patients treated with bevacizumab compared to the placebo control group. Although this strategy has demonstrated delayed tumor progression in some patients, the results are more modest than predicted. Several mechanisms of resistance have been recently proposed and emerging evidence indicates that, under certain experimental conditions, antiangiogenic agents increase intratumoral hypoxia by promoting vessel pruning and inhibiting neoangiogenesis [251].

In near future, the collection and dissemination of molecular targeted therapy research in gastric cancer will provide insight into the molecular understanding of gastric carcinogenesis and interconnectedness of biological processes and allow rapid correlation with clinical data, accelerating the impact on gastric cancer diagnosis, prognostication and treatment.

\section{Author details}

Sun-Mi Lee ${ }^{1}$, Kyoung-Mee Kim² and Jae Y. Ro $^{3^{*}}$

*Address all correspondence to: jaero@tmhs.org

1 Departments of Pathology, University of Texas Health Science Center at San Antonio, San Antonio, TX, USA

2 SamSung Medical Center, SungKunkwan University School of Medicine, Seoul, Korea

3 The Methodist Hospital, Weill Medical College of Cornell University, Houston, TX, USA

\section{References}

[1] Kamangar, F., G.M. Dores, and W.F. Anderson, Patterns of cancer incidence, mortality, and prevalence across five continents: defining priorities to reduce cancer dispari- 
ties in different geographic regions of the world. J Clin Oncol, 2006. 24(14): p. 2137-50.

[2] Siegel, R., D. Naishadham, and A. Jemal, Cancer statistics, 2012. CA Cancer J Clin, 2012. 62(1): p. 10-29.

[3] NCI. SEER Cancer Statistics Review,1975-2009. http://seer.cancer.gov/csr/ 1975_2009_pops09/ 2012.

[4] Yamaoka, Y., M. Kato, and M. Asaka, Geographic differences in gastric cancer incidence can be explained by differences between Helicobacter pylori strains. Intern Med, 2008. 47(12): p. 1077-83.

[5] Ferlay, J., et al., GLOBOCAN 2002 cancer incidence, mortality and prevalence worldwide. version 2.0 ed. IARC cancer base no.5. 2004, Lyon: IARC Press.

[6] Piazuelo, M.B., M. Epplein, and P. Correa, Gastric cancer: an infectious disease. Infect Dis Clin North Am, 2010. 24(4): p. 853-69, vii.

[7] Hisamichi, S., Screening for gastric cancer. World J Surg, 1989. 13(1): p. 31-7.

[8] Sue-Ling, H.M., et al., Early gastric cancer: 46 cases treated in one surgical department. Gut, 1992. 33(10): p. 1318-22.

[9] Devesa, S.S., W.J. Blot, and J.F. Fraumeni, Jr., Changing patterns in the incidence of esophageal and gastric carcinoma in the United States. Cancer, 1998. 83(10): p. 2049-53.

[10] Wijetunge, S., et al., Association of adenocarcinomas of the distal esophagus, "gastroesophageal junction," and "gastric cardia" with gastric pathology. Am J Surg Pathol, 2010. 34(10): p. 1521-7.

[11] Edge SB, Byrd DR, and Compton CC, AJCC Cancer Staging Manual. 7th ed. 2009, New York: Springer-Verlag. 103-115.

[12] Tokunaga, M., et al., Impact of esophageal invasion on clinicopathological characteristics and long-term outcome of adenocarcinoma of the subcardia. J Surg Oncol, 2012.

[13] Steup, W.H., et al., Tumors of the esophagogastric junction. Long-term survival in relation to the pattern of lymph node metastasis and a critical analysis of the accuracy or inaccuracy of pTNM classification. J Thorac Cardiovasc Surg, 1996. 111(1): p. 85-94; discussion 94-5.

[14] Crew, K.D. and A.I. Neugut, Epidemiology of upper gastrointestinal malignancies. Semin Oncol, 2004. 31(4): p. 450-64.

[15] Devesa, S.S. and J.F. Fraumeni, Jr., The rising incidence of gastric cardia cancer. J Natl Cancer Inst, 1999. 91(9): p. 747-9.

[16] Blot, W.J., et al., Rising incidence of adenocarcinoma of the esophagus and gastric cardia. JAMA, 1991. 265(10): p. 1287-9. 
[17] Liu, Y., S. Kaneko, and T. Sobue, Trends in reported incidences of gastric cancer by tumour location, from 1975 to 1989 in Japan. Int J Epidemiol, 2004. 33(4): p. 808-15.

[18] Cunningham, D., et al., Perioperative chemotherapy versus surgery alone for resectable gastroesophageal cancer. N Engl J Med, 2006. 355(1): p. 11-20.

[19] DeMeester, S.R., Adenocarcinoma of the esophagus and cardia: a review of the disease and its treatment. Ann Surg Oncol, 2006. 13(1): p. 12-30.

[20] Kattan, M.W., et al., Postoperative nomogram for disease-specific survival after an R0 resection for gastric carcinoma. J Clin Oncol, 2003. 21(19): p. 3647-50.

[21] Maeda, H., et al., Clinicopathologic features of adenocarcinoma at the gastric cardia: is it different from distal cancer of the stomach? J Am Coll Surg, 2008. 206(2): p. 306-10.

[22] MacDonald, W.C. and J.B. MacDonald, Adenocarcinoma of the esophagus and/or gastric cardia. Cancer, 1987. 60(5): p. 1094-8.

[23] Gray, J.R., A.J. Coldman, and W.C. MacDonald, Cigarette and alcohol use in patients with adenocarcinoma of the gastric cardia or lower esophagus. Cancer, 1992. 69(9): p. 2227-31.

[24] Husemann, B., Cardia carcinoma considered as a distinct clinical entity. Br J Surg, 1989. 76(2): p. 136-9.

[25] Kajiyama, Y., et al., Prognostic factors in adenocarcinoma of the gastric cardia: pathologic stage analysis and multivariate regression analysis. J Clin Oncol, 1997. 15(5): p. 2015-21.

[26] Ohno, S., et al., Clinicopathologic characteristics and outcome of adenocarcinoma of the human gastric cardia in comparison with carcinoma of other regions of the stomach. J Am Coll Surg, 1995. 180(5): p. 577-82.

[27] Lagergren, J., et al., Symptomatic gastroesophageal reflux as a risk factor for esophageal adenocarcinoma. N Engl J Med, 1999. 340(11): p. 825-31.

[28] Inomata, Y., et al., Preservation of gastric acid secretion may be important for the development of gastroesophageal junction adenocarcinoma in Japanese people, irrespective of the H. pylori infection status. Am J Gastroenterol, 2006. 101(5): p. 926-33.

[29] Kamada, T., et al., Relationship between Gastroesophageal Junction Adenocarcinoma and Helicobacter pylori Infection in Japan. Digestion, 2012. 85: p. 256-60.

[30] Siewert, J.R. and H.J. Stein, Classification of adenocarcinoma of the oesophagogastric junction. Br J Surg, 1998. 85(11): p. 1457-9.

[31] International Classification of Disease. 9th Revision. Clinical Modification (ICD-9CM). 6th ed. 2008, Maryland: National Center for Health Statistics. 
[32] Leers, J.M., et al., Clinical characteristics, biologic behavior, and survival after esophagectomy are similar for adenocarcinoma of the gastroesophageal junction and the distal esophagus. J Thorac Cardiovasc Surg, 2009. 138(3): p. 594-602; discussion 601-2.

[33] Gertler, R., et al., How to classify adenocarcinomas of the esophagogastric junction: as esophageal or gastric cancer? Am J Surg Pathol, 2011. 35(10): p. 1512-22.

[34] Hirota, T., S. Ming, and M. Itabashi, Pathology of early gastric carcinoma, 1993, Tokyo: Springer-Verlag. 66-86.

[35] Fujita, S., Biology of early gastric carcinoma. Pathol Res Pract, 1978. 163(4): p. 297-309.

[36] Shimizu, S., M. Tada, and K. Kawai, Early gastric cancer: its surveillance and natural course. Endoscopy, 1995. 27(1): p. 27-31.

[37] Holscher, A.H., et al., Early gastric cancer: lymph node metastasis starts with deep mucosal infiltration. Ann Surg, 2009. 250(5): p. 791-7.

[38] Lawrence, M. and M.H. Shiu, Early gastric cancer. Twenty-eight-year experience. Ann Surg, 1991. 213(4): p. 327-34.

[39] Fielding, J.W., et al., Natural history of "early" gastric cancer: results of a 10-year regional survey. Br Med J, 1980. 281(6246): p. 965-7.

[40] Oliveira, F.J., et al., Early gastric cancer: Report of 58 cases. Gastric Cancer, 1998. 1(1): p. 51-56.

[41] Traynor, O.J., et al., Diagnostic and prognostic problems in early gastric cancer. Am J Surg, 1987. 154(5): p. 516-9.

[42] Axon, A., Symptoms and diagnosis of gastric cancer at early curable stage. Best Pract Res Clin Gastroenterol, 2006. 20(4): p. 697-708.

[43] Taylor, R.H., et al., Misleading response of malignant gastric ulcers to cimetidine. Lancet, 1978. 1(8066): p. 686-8.

[44] Wayman, J., N. Hayes, and S.M. Griffin, The response of early gastric cancer to proton-pump inhibitors. N Engl J Med, 1998. 338(26): p. 1924-5.

[45] Sakita, T., et al., Observations on the healing of ulcerations in early gastric cancer. The life cycle of the malignant ulcer. Gastroenterology, 1971. 60(5): p. 835-9 passim.

[46] Tsukuma, H., et al., Natural history of early gastric cancer: a non-concurrent, long term, follow up study. Gut, 2000. 47(5): p. 618-21.

[47] Kohli, Y., K. Kawai, and S. Fujita, Analytical studies on growth of human gastric cancer. J Clin Gastroenterol, 1981. 3(2): p. 129-33.

[48] Kikuchi, S., et al., Survival after surgical treatment of early gastric cancer: surgical techniques and long-term survival. Langenbecks Arch Surg, 2004. 389(2): p. 69-74. 
[49] Onodera, H., et al., Surgical outcome of 483 patients with early gastric cancer: prognosis, postoperative morbidity and mortality, and gastric remnant cancer. Hepatogastroenterology, 2004. 51(55): p. 82-5.

[50] Moreaux, J. and J. Bougaran, Early gastric cancer. A 25-year surgical experience. Ann Surg, 1993. 217(4): p. 347-55.

[51] Sano, T., et al., Recurrence of early gastric cancer. Follow-up of 1475 patients and review of the Japanese literature. Cancer, 1993. 72(11): p. 3174-8.

[52] Kurihara, M., et al., Diagnosis of small early gastric cancer by $\mathrm{X}$-ray, endoscopy, and biopsy. Cancer Detect Prev, 1981. 4(1-4): p. 377-83.

[53] Ito, Y., et al., The endoscopic diagnosis of early gastric cancer. Gastrointest Endosc, 1979. 25(3): p. 96-101.

[54] Maehara, Y., et al., Predictors of lymph node metastasis in early gastric cancer. Br J Surg, 1992. 79(3): p. 245-7.

[55] Yasuda, K., et al., Rate of detection of lymph node metastasis is correlated with the depth of submucosal invasion in early stage gastric carcinoma. Cancer, 1999. 85(10): p. 2119-23.

[56] Choi, J., et al., Endoscopic prediction of tumor invasion depth in early gastric cancer. Gastrointest Endosc, 2011. 73(5): p. 917-27.

[57] Ono, H. and S. Yohida, Endoscopic diagnosis of the depth of cancer invasion for gastric cancer. Stomach Intestine, 2001. 36: p. 6.

[58] Yanai, H., et al., Endoscopic ultrasonography and endoscopy for staging depth of invasion in early gastric cancer: a pilot study. Gastrointest Endosc, 1997. 46(3): p. 212-6.

[59] Kim, J.H., et al., Clinicopathologic factors influence accurate endosonographic assessment for early gastric cancer. Gastrointest Endosc, 2007. 66(5): p. 901-8.

[60] Lewin, K.J. and H.D. Appleman, Tumors of the esophagus and stomach, ed. J. Rosai. 1996, Washington D.C.: Armed Forces Institute of Pathology.

[61] Biasco, G., et al., Early gastric cancer in Italy. Clinical and pathological observations on 80 cases. Dig Dis Sci, 1987. 32(2): p. 113-20.

[62] Nakamura, K. and H. Sugano, Microcarcinoma of the stomach measuring less than 5 $\mathrm{mm}$ in the largest diameter and its histogenesis. Prog Clin Biol Res, 1983. 132D: p. 107-16.

[63] Shiroshita, H., et al., Re-evaluation of mucin phenotypes of gastric minute well-differentiated-type adenocarcinomas using a series of HGM, MUC5AC, MUC6, MGGMC, MUC2 and CD10 stains. Pathol Int, 2004. 54(5): p. 311-21.

[64] Mori, M., M. Enjoji, and K. Sugimachi, Histopathologic features of minute and small human gastric adenocarcinomas. Arch Pathol Lab Med, 1989. 113(8): p. 926-31. 
[65] Otsuji, E., et al., Clinicopathologic characteristics and prognosis of synchronous multifocal gastric carcinomas. Am J Surg, 2005. 189(1): p. 116-9.

[66] Choi, J., et al., Lymph node metastasis in multiple synchronous early gastric cancer. Gastrointest Endosc, 2011. 74(2): p. 276-84.

[67] Oohara, T., et al., Clinical diagnosis of minute gastric cancer less than $5 \mathrm{~mm}$ in diameter. Cancer, 1984. 53(1): p. 162-5.

[68] Hirota, T., et al., Clinicopathologic study of minute and small early gastric cancer. Histogenesis of gastric cancer. Pathol Annu, 1980. 15(Pt 2): p. 1-19.

[69] Ishida, M., et al., Metachronous liver metastasis from early gastric cancer. J Gastrointest Surg, 2012. 16(4): p. 837-41.

[70] Japanese classification of gastric carcinoma: 3rd English edition. Gastric Cancer, 2011. 14(2): p. 101-12.

[71] Update on the Paris classification of superficial neoplastic lesions in the digestive tract. Endoscopy, 2005. 37(6): p. 570-8.

[72] Tan, Y.K. and J.W. Fielding, Early diagnosis of early gastric cancer. Eur J Gastroenterol Hepatol, 2006. 18(8): p. 821-9.

[73] Xuan, Z.X., et al., Time trends of early gastric carcinoma. A clinicopathologic analysis of 2846 cases. Cancer, 1993. 72(10): p. 2889-94.

[74] Craanen, M.E., et al., Early gastric cancer: a clinicopathologic study. J Clin Gastroenterol, 1991. 13(3): p. 274-83.

[75] Everett, S.M. and A.T. Axon, Early gastric cancer: disease or pseudo-disease? Lancet, 1998. 351(9112): p. 1350-2.

[76] Sung, J., Early gastric cancer: diagnosis, treatment and prevention. Eur J Gastroenterol Hepatol, 2006. 18(8): p. 817-9.

[77] Srivastava, A. and G.Y. Lauwers, Gastric epithelial dysplasia: the Western perspective. Dig Liver Dis, 2008. 40(8): p. 641-9.

[78] Schlemper, R.J., et al., The Vienna classification of gastrointestinal epithelial neoplasia. Gut, 2000. 47(2): p. 251-5.

[79] Gotoda, T., et al., Incidence of lymph node metastasis from early gastric cancer: estimation with a large number of cases at two large centers. Gastric Cancer, 2000. 3(4): p. 219-225.

[80] Tsujitani, S., et al., Less invasive surgery for early gastric cancer based on the low probability of lymph node metastasis. Surgery, 1999. 125(2): p. 148-54.

[81] Kim, S.G., Endoscopic treatment for early gastric cancer. J Gastric Cancer, 2011. 11(3): p. 146-54. 
[82] Soetikno, R., et al., Endoscopic mucosal resection for early cancers of the upper gastrointestinal tract. J Clin Oncol, 2005. 23(20): p. 4490-8.

[83] Sugano, K., Gastric cancer: pathogenesis, screening, and treatment. Gastrointest Endosc Clin N Am, 2008. 18(3): p. 513-22, ix.

[84] Hirasawa, T., et al., Incidence of lymph node metastasis and the feasibility of endoscopic resection for undifferentiated-type early gastric cancer. Gastric Cancer, 2009. 12(3): p. 148-52.

[85] Ahn, J.Y., et al., Endoscopic and oncologic outcomes after endoscopic resection for early gastric cancer: 1370 cases of absolute and extended indications. Gastrointest Endosc, 2011. 74(3): p. 485-93.

[86] Ono, H., Early gastric cancer: diagnosis, pathology, treatment techniques and treatment outcomes. Eur J Gastroenterol Hepatol, 2006. 18(8): p. 863-6.

[87] Rembacken, B.J., et al., Endoscopic mucosal resection. Endoscopy, 2001. 33(8): p. 709-18.

[88] Alfaro, E.E. and G.Y. Lauwers, Early gastric neoplasia: diagnosis and implications. Adv Anat Pathol, 2011. 18(4): p. 268-80.

[89] Amano, Y., et al., An assessment of local curability of endoscopic surgery in early gastric cancer without satisfaction of current therapeutic indications. Endoscopy, 1998. 30(6): p. 548-52.

[90] Habu, H., et al., Lymph node metastasis in early gastric cancer. Int Surg, 1986. 71(4): p. 244-7.

[91] Ishigami, S., et al., Carcinomatous lymphatic invasion in early gastric cancer invading into the submucosa. Ann Surg Oncol, 1999. 6(3): p. 286-9.

[92] Ono, H., et al., Endoscopic mucosal resection for treatment of early gastric cancer. Gut, 2001. 48(2): p. 225-9.

[93] Oka, S., et al., Advantage of endoscopic submucosal dissection compared with EMR for early gastric cancer. Gastrointest Endosc, 2006. 64(6): p. 877-83.

[94] Tanabe, S., et al., Clinical outcome of endoscopic aspiration mucosectomy for early stage gastric cancer. Gastrointest Endosc, 2002. 56(5): p. 708-13.

[95] Manner, H., et al., Long-term results of endoscopic resection in early gastric cancer: the Western experience. Am J Gastroenterol, 2009. 104(3): p. 566-73.

[96] Watanabe, K., et al., Clinical outcomes of EMR for gastric tumors: historical pilot evaluation between endoscopic submucosal dissection and conventional mucosal resection. Gastrointest Endosc, 2006. 63(6): p. 776-82.

[97] Isomoto, H., et al., Endoscopic submucosal dissection for early gastric cancer: a largescale feasibility study. Gut, 2009. 58(3): p. 331-6. 
[98] Goto, O., et al., Outcomes of endoscopic submucosal dissection for early gastric cancer with special reference to validation for curability criteria. Endoscopy, 2009. 41(2): p. 118-22.

[99] Mitsuhashi, T., et al., Post-gastric endoscopic mucosal resection surveillance biopsies: evaluation of mucosal changes and recognition of potential mimics of residual adenocarcinoma. Am J Surg Pathol, 2006. 30(5): p. 650-6.

[100] Clark, C.J., et al., Current problems in surgery: gastric cancer. Curr Probl Surg, 2006. 43(8-9): p. 566-670.

[101] Abeloff, M.D., et al., Abeloff's Clinical Oncology, ed. M.D. Abeloff. 2008, Philadelphia: Churchill Livingstone.

[102] Stemmermann, G.N., Extrapelvic carcinoma metastatic to the uterus. Am J Obstet Gynecol, 1961. 82: p. 1261-6.

[103] Catalano, V., et al., Gastric cancer. Crit Rev Oncol Hematol, 2009. 71(2): p. 127-64.

[104] Kurtz, R.C. and P. Sherlock, The diagnosis of gastric cancer. Semin Oncol, 1985. 12(1): p. 11-8.

[105] Wanebo, H.J., et al., Cancer of the stomach. A patient care study by the American College of Surgeons. Ann Surg, 1993. 218(5): p. 583-92.

[106] Shah, M.A., Gastric cancer: an update. Curr Oncol Rep, 2006. 8(3): p. 183-91.

[107] Low, V.H., et al., Diagnosis of gastric carcinoma: sensitivity of double-contrast barium studies. AJR Am J Roentgenol, 1994. 162(2): p. 329-34.

[108] Halvorsen, R.A., Jr., J. Yee, and V.D. McCormick, Diagnosis and staging of gastric cancer. Semin Oncol, 1996. 23(3): p. 325-35.

[109] Takao, M., et al., Discrepancies in histologic diagnoses of early gastric cancer between biopsy and endoscopic mucosal resection specimens. Gastric Cancer, 2012. 15(1): p. 91-6.

[110] Hakama, M., et al., Tumour markers and screening for gastrointestinal cancer: a follow up study in Finland. J Med Screen, 1994. 1(1): p. 60-4.

[111] Pectasides, D., et al., CEA, CA 19-9, and CA-50 in monitoring gastric carcinoma. Am J Clin Oncol, 1997. 20(4): p. 348-53.

[112] Willis, S., et al., Endoscopic ultrasonography in the preoperative staging of gastric cancer: accuracy and impact on surgical therapy. Surg Endosc, 2000. 14(10): p. 951-4.

[113] Kelly, S., et al., A systematic review of the staging performance of endoscopic ultrasound in gastro-oesophageal carcinoma. Gut, 2001. 49(4): p. 534-9.

[114] Bhandari, S., et al., Usefulness of three-dimensional, multidetector row CT (virtual gastroscopy and multiplanar reconstruction) in the evaluation of gastric cancer: a 
comparison with conventional endoscopy, EUS, and histopathology. Gastrointest Endosc, 2004. 59(6): p. 619-26.

[115] Paramo, J.C. and G. Gomez, Dynamic CT in the preoperative evaluation of patients with gastric cancer: correlation with surgical findings and pathology. Ann Surg Oncol, 1999. 6(4): p. 379-84.

[116] Davies, J., et al., Spiral computed tomography and operative staging of gastric carcinoma: a comparison with histopathological staging. Gut, 1997. 41(3): p. 314-9.

[117] Sohn, K.M., et al., Comparing MR imaging and CT in the staging of gastric carcinoma. AJR Am J Roentgenol, 2000. 174(6): p. 1551-7.

[118] Kim, A.Y., et al., MRI in staging advanced gastric cancer: is it useful compared with spiral CT? J Comput Assist Tomogr, 2000. 24(3): p. 389-94.

[119] Borrmann, R., Handbuch der Speziellen Patho-logischen Anatomie und Histologie. Geshwulste des Magens und Duodenums, 1926: p. 865.

[120] Ming, S., Classification of gastric carcinoma. Gastric Carcinoma, ed. M. Filipe and J. Jass. 1986, Edinburgh: Carleston-Livingston. 3.

[121] Lauren, P., The Two Histological Main Types of Gastric Carcinoma: Diffuse and SoCalled Intestinal-Type Carcinoma. An Attempt at a Histo-Clinical Classification. Acta Pathol Microbiol Scand, 1965. 64: p. 31-49.

[122] Noda, S., K. Soejima, and K. Inokuchi, Clinicopathological analysis of the intestinal type and diffuse type of gastric carcinoma. Jpn J Surg, 1980. 10(4): p. 277-83.

[123] Vauhkonen, M., H. Vauhkonen, and P. Sipponen, Pathology and molecular biology of gastric cancer. Best Pract Res Clin Gastroenterol, 2006. 20(4): p. 651-74.

[124] Correa, P., Human gastric carcinogenesis: a multistep and multifactorial process-First American Cancer Society Award Lecture on Cancer Epidemiology and Prevention. Cancer Res, 1992. 52(24): p. 6735-40.

[125] Carneiro, F., et al., Model of the early development of diffuse gastric cancer in E-cadherin mutation carriers and its implications for patient screening. J Pathol, 2004. 203(2): p. 681-7.

[126] Houghton, J., et al., Gastric cancer originating from bone marrow-derived cells. Science, 2004. 306(5701): p. 1568-71.

[127] Guilford, P., B. Humar, and V. Blair, Hereditary diffuse gastric cancer: translation of CDH1 germline mutations into clinical practice. Gastric Cancer, 2010. 13(1): p. 1-10.

[128] Oliveira, C., et al., Genetic screening for familial gastric cancer. Hered Cancer Clin Pract, 2004. 2(2): p. 51-64.

[129] Borch, K., et al., Changing pattern of histological type, location, stage and outcome of surgical treatment of gastric carcinoma. Br J Surg, 2000. 87(5): p. 618-26. 
[130] Stelzner, S. and P. Emmrich, The mixed type in Lauren's classification of gastric carcinoma. Histologic description and biologic behavior. Gen Diagn Pathol, 1997. 143(1): p. 39-48.

[131] Zheng, H.C., et al., Mixed-type gastric carcinomas exhibit more aggressive features and indicate the histogenesis of carcinomas. Virchows Arch, 2008. 452(5): p. 525-34.

[132] Kozuki, T., et al., Differences in p53 and cadherin-catenin complex expression between histological subtypes in diffusely infiltrating gastric carcinoma. Histopathology, 2002. 41(1): p. 56-64.

[133] Ming, S.C., Gastric carcinoma. A pathobiological classification. Cancer, 1977. 39(6): p. 2475-85.

[134] Davessar, K., et al., Gastric adenocarcinoma: prognostic significance of several pathologic parameters and histologic classifications. Hum Pathol, 1990. 21(3): p. 325-32.

[135] Goseki, N., T. Takizawa, and M. Koike, Differences in the mode of the extension of gastric cancer classified by histological type: new histological classification of gastric carcinoma. Gut, 1992. 33(5): p. 606-12.

[136] Songun, I., et al., Classification of gastric carcinoma using the Goseki system provides prognostic information additional to TNM staging. Cancer, 1999. 85(10): p. 2114-8.

[137] Dixon, M.F., et al., Goseki grading in gastric cancer: comparison with existing systems of grading and its reproducibility. Histopathology, 1994. 25(4): p. 309-16.

[138] Martin, I.G., et al., Goseki histological grading of gastric cancer is an important predictor of outcome. Gut, 1994. 35(6): p. 758-63.

[139] Roy, P., et al., Prognostic comparison of the pathological classifications of gastric cancer: a population-based study. Histopathology, 1998. 33(4): p. 304-10.

[140] Guglielmi, A., et al., [Prognostic value of histologic classifications of advanced stomach cancer: comparative study of Lauren's and Goseki's classifications]. Chir Ital, 1997. 49(3): p. 45-9.

[141] WHO, Tumors of the digestive system. World Health Organization classification of tumors, ed. S.R. Hamilton and L.A. Aaltonen. 2000, Lyon: IARC Press. 37-68.

[142] Adachi, Y., et al., Pathology and prognosis of gastric carcinoma: well versus poorly differentiated type. Cancer, 2000. 89(7): p. 1418-24.

[143] Kuroda, T., et al., Presence of poorly differentiated component correlated with submucosal invasion in the early diffuse-type gastric cancer. Hepatogastroenterology, 2008. 55(88): p. 2264-8.

[144] Wu, C.Y., et al., Lymph node metastasis in early gastric cancer: a clinicopathological analysis. Hepatogastroenterology, 2002. 49(47): p. 1465-8. 
[145] Watanabe, H., J. Jass, and L. Sobin, Histological typing of oesophageal and gastric tumors. 2nd ed. WHO international histological classification of tumors. 1990, Berlin: Springer-Verlag.

[146] Carneiro, F., M. Seixas, and M. Sobrinho-Simoes, New elements for an updated classification of the carcinomas of the stomach. Pathol Res Pract, 1995. 191(6): p. 571-84.

[147] Yasuda, K., et al., Papillary adenocarcinoma of the stomach. Gastric Cancer, 2000. 3(1): p. 33-38.

[148] Hirota, T., A. Ochiai, and M. Itabashi, Significance of histological type of gastric carcinoma as a prognostic factor. Stomach Intestine, 1991. 26: p. 9.

[149] Ito, E., T. Takizawa, and N. Shiraishi, Differentiated adenocarcinoma of the gastric and intestinal phenotype-histological appearance and biological behavior. Stomach Intestine, 2003. 38: p. 6.

[150] Nakashima, Y., et al., Nuclear atypia grading score is a useful prognostic factor in papillary gastric adenocarcinoma. Histopathology, 2011. 59(5): p. 841-9.

[151] Kunisaki, C., et al., Clinicopathologic characteristics and surgical outcomes of mucinous gastric carcinoma. Ann Surg Oncol, 2006. 13(6): p. 836-42.

[152] Adachi, Y., et al., A clinicopathologic study of mucinous gastric carcinoma. Cancer, 1992. 69(4): p. 866-71.

[153] $\mathrm{Wu}, \mathrm{C} . Y .$, et al., A clinicopathologic study of mucinous gastric carcinoma including multivariate analysis. Cancer, 1998. 83(7): p. 1312-8.

[154] Sung, C.O., et al., Tumor size predicts survival in mucinous gastric carcinoma. J Surg Oncol, 2012.

[155] Li, C., et al., Advanced gastric carcinoma with signet ring cell histology. Oncology, 2007. 72(1-2): p. 64-8.

[156] Hyung, W.J., et al., Early gastric carcinoma with signet ring cell histology. Cancer, 2002. 94(1): p. 78-83.

[157] Ho, S.B., et al., Mucin gene expression in normal, preneoplastic, and neoplastic human gastric epithelium. Cancer Res, 1995. 55(12): p. 2681-90.

[158] Ho, S.B., et al., Heterogeneity of mucin gene expression in normal and neoplastic tissues. Cancer Res, 1993. 53(3): p. 641-51.

[159] Reis, C.A., et al., Immunohistochemical study of MUC5AC expression in human gastric carcinomas using a novel monoclonal antibody. Int J Cancer, 1997. 74(1): p. $112-21$.

[160] Reis, C.A., et al., Expression of fully and under-glycosylated forms of MUC1 mucin in gastric carcinoma. Int J Cancer, 1998. 79(4): p. 402-10. 
[161] Sakamoto, H., et al., Mucin antigen expression in gastric carcinomas of young and old adults. Hum Pathol, 1997. 28(9): p. 1056-65.

[162] Reis, C.A., et al., Immunohistochemical study of the expression of MUC6 mucin and co-expression of other secreted mucins (MUC5AC and MUC2) in human gastric carcinomas. J Histochem Cytochem, 2000. 48(3): p. 377-88.

[163] Buisine, M.P., et al., Developmental mucin gene expression in the gastroduodenal tract and accessory digestive glands. I. Stomach. A relationship to gastric carcinoma. J Histochem Cytochem, 2000. 48(12): p. 1657-66.

[164] Pinto-de-Sousa, J., et al., Mucins MUC1, MUC2, MUC5AC and MUC6 expression in the evaluation of differentiation and clinico-biological behaviour of gastric carcinoma. Virchows Arch, 2002. 440(3): p. 304-10.

[165] Fiocca, R., et al., Characterization of four main cell types in gastric cancer: foveolar, mucopeptic, intestinal columnar and goblet cells. An histopathologic, histochemical and ultrastructural study of "early" and "advanced" tumours. Pathol Res Pract, 1987. 182(3): p. 308-25.

[166] Pinto-de-Sousa, J., et al., MUC5B expression in gastric carcinoma: relationship with clinico-pathological parameters and with expression of mucins MUC1, MUC2, MUC5AC and MUC6. Virchows Arch, 2004. 444(3): p. 224-30.

[167] Lee, H.S., et al., MUC1, MUC2, MUC5AC, and MUC6 expressions in gastric carcinomas: their roles as prognostic indicators. Cancer, 2001. 92(6): p. 1427-34.

[168] Taniere, P., et al., Cytokeratin expression in adenocarcinomas of the esophagogastric junction: a comparative study of adenocarcinomas of the distal esophagus and of the proximal stomach. Am J Surg Pathol, 2002. 26(9): p. 1213-21.

[169] Wang, K., et al., Exome sequencing identifies frequent mutation of ARID1A in molecular subtypes of gastric cancer. Nat Genet, 2011. 43(12): p. 1219-23.

[170] Zang, Z.J., et al., Exome sequencing of gastric adenocarcinoma identifies recurrent somatic mutations in cell adhesion and chromatin remodeling genes. Nat Genet, 2012. 44(5): p. 570-4.

[171] Lee, J., et al., High-throughput mutation profiling identifies frequent somatic mutations in advanced gastric adenocarcinoma. PLoS One, 2012. 7(6): p. e38892.

[172] MacConaill, L.E., et al., Profiling critical cancer gene mutations in clinical tumor samples. PLoS One, 2009. 4(11): p. e7887.

[173] Jones, S., et al., Somatic mutations in the chromatin remodeling gene ARID1A occur in several tumor types. Hum Mutat, 2012. 33(1): p. 100-3.

[174] Abe, H., et al., ARID1A expression loss in gastric cancer: pathway-dependent roles with and without Epstein-Barr virus infection and microsatellite instability. Virchows Arch, 2012. 
[175] Reisman, D., S. Glaros, and E.A. Thompson, The SWI/SNF complex and cancer. Oncogene, 2009. 28(14): p. 1653-68.

[176] Huang, J., et al., Genomic and functional evidence for an ARID1A tumor suppressor role. Genes Chromosomes Cancer, 2007. 46(8): p. 745-50.

[177] Jones, S., et al., Frequent mutations of chromatin remodeling gene ARID1A in ovarian clear cell carcinoma. Science, 2010. 330(6001): p. 228-31.

[178] Wiegand, K.C., et al., ARID1A mutations in endometriosis-associated ovarian carcinomas. N Engl J Med, 2010. 363(16): p. 1532-43.

[179] Oshima, T. and M. Masuda, Molecular targeted agents for gastric and gastroesophageal junction cancer. Surg Today, 2012. 42(4): p. 313-27.

[180] Nakajima, M., et al., The prognostic significance of amplification and overexpression of c-met and c-erb B-2 in human gastric carcinomas. Cancer, 1999. 85(9): p. 1894-902.

[181] Panani, A.D., Cytogenetic and molecular aspects of gastric cancer: clinical implications. Cancer Lett, 2008. 266(2): p. 99-115.

[182] Kuniyasu, H., et al., Frequent amplification of the c-met gene in scirrhous type stomach cancer. Biochem Biophys Res Commun, 1992. 189(1): p. 227-32.

[183] Kuniyasu, H., et al., Aberrant expression of c-met mRNA in human gastric carcinomas. Int J Cancer, 1993. 55(1): p. 72-5.

[184] Huang, T.J., et al., Overexpression of the c-met protooncogene in human gastric carcinoma--correlation to clinical features. Acta Oncol, 2001. 40(5): p. 638-43.

[185] Smith, M.G., et al., Cellular and molecular aspects of gastric cancer. World J Gastroenterol, 2006. 12(19): p. 2979-90.

[186] Hattori, Y., et al., K-sam, an amplified gene in stomach cancer, is a member of the heparin-binding growth factor receptor genes. Proc Natl Acad Sci U S A, 1990. 87(15): p. 5983-7.

[187] Hara, T., et al., Amplification of c-myc, K-sam, and c-met in gastric cancers: detection by fluorescence in situ hybridization. Lab Invest, 1998. 78(9): p. 1143-53.

[188] Yokota, J., et al., Genetic alterations of the c-erbB-2 oncogene occur frequently in tubular adenocarcinoma of the stomach and are often accompanied by amplification of the v-erbA homologue. Oncogene, 1988. 2(3): p. 283-7.

[189] Rhyu, M.G., et al., Allelic deletions of MCC/APC and p53 are frequent late events in human gastric carcinogenesis. Gastroenterology, 1994. 106(6): p. 1584-8.

[190] Wu, M.S., et al., Genetic alterations in gastric cancer: relation to histological subtypes, tumor stage, and Helicobacter pylori infection. Gastroenterology, 1997. 112(5): p. 1457-65. 
[191] Brito, M.J., et al., Expression of p53 in early (T1) gastric carcinoma and precancerous adjacent mucosa. Gut, 1994. 35(12): p. 1697-700.

[192] Horii, A., et al., The APC gene, responsible for familial adenomatous polyposis, is mutated in human gastric cancer. Cancer Res, 1992. 52(11): p. 3231-3.

[193] Hsieh, L.L. and Y.C. Huang, Loss of heterozygosity of APC/MCC gene in differentiated and undifferentiated gastric carcinomas in Taiwan. Cancer Lett, 1995. 96(2): p. 169-74.

[194] Chi, X.Z., et al., RUNX3 suppresses gastric epithelial cell growth by inducing p21(WAF1/Cip1) expression in cooperation with transforming growth factor beta\}activated SMAD. Mol Cell Biol, 2005. 25(18): p. 8097-107.

[195] Kim, T.Y., et al., Methylation of RUNX3 in various types of human cancers and premalignant stages of gastric carcinoma. Lab Invest, 2004. 84(4): p. 479-84.

[196] Sakakura, C., et al., Frequent downregulation of the runt domain transcription factors RUNX1, RUNX3 and their cofactor CBFB in gastric cancer. Int J Cancer, 2005. 113(2): p. 221-8.

[197] Maehama, T. and J.E. Dixon, The tumor suppressor, PTEN/MMAC1, dephosphorylates the lipid second messenger, phosphatidylinositol 3,4,5-trisphosphate. J Biol Chem, 1998. 273(22): p. 13375-8.

[198] Blanco-Aparicio, C., et al., PTEN, more than the AKT pathway. Carcinogenesis, 2007. 28(7): p. 1379-86.

[199] Im, S.A., et al., Potential prognostic significance of p185(HER2) overexpression with loss of PTEN expression in gastric carcinomas. Tumori, 2005. 91(6): p. 513-21.

[200] Zhou, Y.J., et al., Inactivation of PTEN is associated with increased angiogenesis and VEGF overexpression in gastric cancer. World J Gastroenterol, 2004. 10(21): p. 3225-9.

[201] Zheng, H.C., et al., Role of PTEN and MMP-7 expression in growth, invasion, metastasis and angiogenesis of gastric carcinoma. Pathol Int, 2003. 53(10): p. 659-66.

[202] Esteva, F.J., et al., PTEN, PIK3CA, p-AKT, and p-p70S6K status: association with trastuzumab response and survival in patients with HER2-positive metastatic breast cancer. Am J Pathol, 2010. 177(4): p. 1647-56.

[203] Mayer, B., et al., E-cadherin expression in primary and metastatic gastric cancer: down-regulation correlates with cellular dedifferentiation and glandular disintegration. Cancer Res, 1993. 53(7): p. 1690-5.

[204] Ascano, J.J., et al., Inactivation of the E-cadherin gene in sporadic diffuse-type gastric cancer. Mod Pathol, 2001. 14(10): p. 942-9.

[205] Suriano, G., et al., The intracellular E-cadherin germline mutation V832 M lacks the ability to mediate cell-cell adhesion and to suppress invasion. Oncogene, 2003. 22(36): p. 5716-9. 
[206] Tamura, G., et al., E-Cadherin gene promoter hypermethylation in primary human gastric carcinomas. J Natl Cancer Inst, 2000. 92(7): p. 569-73.

[207] Ebert, M.P., et al., Increased beta-catenin mRNA levels and mutational alterations of the APC and beta-catenin gene are present in intestinal-type gastric cancer. Carcinogenesis, 2002. 23(1): p. 87-91.

[208] Ebert, M.P., et al., Loss of beta-catenin expression in metastatic gastric cancer. J Clin Oncol, 2003. 21(9): p. 1708-14.

[209] Sakata, K., et al., Hypermethylation of the hMLH1 gene promoter in solitary and multiple gastric cancers with microsatellite instability. Br J Cancer, 2002. 86(4): p. 564-7.

[210] Cervantes, A., et al., Molecular biology of gastric cancer. Clin Transl Oncol, 2007. 9(4): p. 208-15.

[211] Kang, G.H., et al., Profile of aberrant CpG island methylation along the multistep pathway of gastric carcinogenesis. Lab Invest, 2003. 83(5): p. 635-41.

[212] Chong, J.M., et al., Microsatellite instability in the progression of gastric carcinoma. Cancer Res, 1994. 54(17): p. 4595-7.

[213] Semba, S., et al., Microsatellite instability in precancerous lesions and adenocarcinomas of the stomach. Cancer, 1996. 77(8 Suppl): p. 1620-7.

[214] Ottini, L., et al., Microsatellite instability in gastric cancer is associated with tumor location and family history in a high-risk population from Tuscany. Cancer Res, 1997. 57(20): p. 4523-9.

[215] Leung, S.Y., et al., hMLH1 promoter methylation and lack of hMLH1 expression in sporadic gastric carcinomas with high-frequency microsatellite instability. Cancer Res, 1999. 59(1): p. 159-64.

[216] Herman, J.G. and S.B. Baylin, Gene silencing in cancer in association with promoter hypermethylation. N Engl J Med, 2003. 349(21): p. 2042-54.

[217] Fleisher, A.S., et al., Hypermethylation of the hMLH1 gene promoter in human gastric cancers with microsatellite instability. Cancer Res, 1999. 59(5): p. 1090-5.

[218] Halling, K.C., et al., Origin of microsatellite instability in gastric cancer. Am J Pathol, 1999. 155(1): p. 205-11.

[219] dos Santos, N.R., et al., Microsatellite instability at multiple loci in gastric carcinoma: clinicopathologic implications and prognosis. Gastroenterology, 1996. 110(1): p. 38-44.

[220] Oliveira, C., et al., The clinicopathological features of gastric carcinomas with microsatellite instability may be mediated by mutations of different "target genes": a study of the TGFbeta RII, IGFII R, and BAX genes. Am J Pathol, 1998. 153(4): p. 1211-9. 
[221] Wu, M.S., et al., Clinicopathological significance of altered loci of replication error and microsatellite instability-associated mutations in gastric cancer. Cancer Res, 1998. 58(7): p. 1494-7.

[222] Kusano, M., et al., Genetic, epigenetic, and clinicopathologic features of gastric carcinomas with the $\mathrm{CpG}$ island methylator phenotype and an association with EpsteinBarr virus. Cancer, 2006. 106(7): p. 1467-79.

[223] Chang, M.S., et al., CpG island methylation status in gastric carcinoma with and without infection of Epstein-Barr virus. Clin Cancer Res, 2006. 12(10): p. 2995-3002.

[224] Enomoto, S., et al., Lack of association between CpG island methylator phenotype in human gastric cancers and methylation in their background non-cancerous gastric mucosae. Cancer Sci, 2007. 98(12): p. 1853-61.

[225] Chong, J.M., et al., Global and non-random CpG-island methylation in gastric carcinoma associated with Epstein-Barr virus. Cancer Sci, 2003. 94(1): p. 76-80.

[226] Leung, S.Y., et al., Microsatellite instability, Epstein-Barr virus, mutation of type II transforming growth factor beta receptor and BAX in gastric carcinomas in Hong Kong Chinese. Br J Cancer, 1999. 79(3-4): p. 582-8.

[227] Chang, M.S., et al., Epstein-Barr virus and microsatellite instability in gastric carcinogenesis. J Pathol, 2003. 199(4): p. 447-52.

[228] Wu, M.S., et al., Epstein-Barr virus-associated gastric carcinomas: relation to H. pylori infection and genetic alterations. Gastroenterology, 2000. 118(6): p. 1031-8.

[229] Park, H.Y., et al., EBV infection and mismatch repair deficiency mediated by loss of hMLH1 expression contribute independently to the development of multiple synchronous gastric carcinomas. J Surg Oncol, 2012.

[230] Yasui, W., et al., Molecular diagnosis of gastric cancer: present and future. Gastric Cancer, 2001. 4(3): p. 113-21.

[231] Yasui, W., et al., Expression of telomerase catalytic component, telomerase reverse transcriptase, in human gastric carcinomas. Jpn J Cancer Res, 1998. 89(11): p. 1099-103.

[232] Yasui, W., et al., Immunohistochemical detection of human telomerase reverse transcriptase in normal mucosa and precancerous lesions of the stomach. Jpn J Cancer Res, 1999. 90(6): p. 589-95.

[233] Herbst, R.S., Review of epidermal growth factor receptor biology. Int J Radiat Oncol Biol Phys, 2004. 59(2 Suppl): p. 21-6.

[234] Bang, Y.J., et al., Trastuzumab in combination with chemotherapy versus chemotherapy alone for treatment of HER2-positive advanced gastric or gastro-oesophageal junction cancer (ToGA): a phase 3, open-label, randomised controlled trial. Lancet, 2010. 376(9742): p. 687-97. 
[235] Yano, T., et al., Comparison of HER2 gene amplification assessed by fluorescence in situ hybridization and HER2 protein expression assessed by immunohistochemistry in gastric cancer. Oncol Rep, 2006. 15(1): p. 65-71.

[236] Lorenzen, S. and F. Lordick, How will human epidermal growth factor receptor 2neu data impact clinical management of gastric cancer? Curr Opin Oncol, 2011. 23(4): p. 396-402.

[237] Park, D.I., et al., HER-2/neu amplification is an independent prognostic factor in gastric cancer. Dig Dis Sci, 2006. 51(8): p. 1371-9.

[238] Yonemura, Y., et al., Evaluation of immunoreactivity for erbB-2 protein as a marker of poor short term prognosis in gastric cancer. Cancer Res, 1991. 51(3): p. 1034-8.

[239] Uchino, S., et al., Overexpression of c-erbB-2 protein in gastric cancer. Its correlation with long-term survival of patients. Cancer, 1993. 72(11): p. 3179-84.

[240] Mizutani, T., et al., Relationship of C-erbB-2 protein expression and gene amplification to invasion and metastasis in human gastric cancer. Cancer, 1993. 72(7): p. 2083-8.

[241] Allgayer, H., et al., c-erbB-2 is of independent prognostic relevance in gastric cancer and is associated with the expression of tumor-associated protease systems. J Clin Oncol, 2000. 18(11): p. 2201-9.

[242] Liu, L., N. Wu, and J. Li, Novel targeted agents for gastric cancer. J Hematol Oncol, 2012. 5: p. 31.

[243] Ferrara, N., H.P. Gerber, and J. LeCouter, The biology of VEGF and its receptors. Nat Med, 2003. 9(6): p. 669-76.

[244] Maeda, K., et al., Prognostic value of vascular endothelial growth factor expression in gastric carcinoma. Cancer, 1996. 77(5): p. 858-63.

[245] Karayiannakis, A.J., et al., Circulating VEGF levels in the serum of gastric cancer patients: correlation with pathological variables, patient survival, and tumor surgery. Ann Surg, 2002. 236(1): p. 37-42.

[246] Hurwitz, H., et al., Bevacizumab plus irinotecan, fluorouracil, and leucovorin for metastatic colorectal cancer. N Engl J Med, 2004. 350(23): p. 2335-42.

[247] Sandler, A., et al., Paclitaxel-carboplatin alone or with bevacizumab for non-smallcell lung cancer. N Engl J Med, 2006. 355(24): p. 2542-50.

[248] Miller, K., et al., Paclitaxel plus bevacizumab versus paclitaxel alone for metastatic breast cancer. N Engl J Med, 2007. 357(26): p. 2666-76.

[249] Spasic, M., et al., Molecular characteristics and pathways of Avastin for the treatment of glioblastoma multiforme. Neurosurg Clin N Am, 2012. 23(3): p. 417-27. 
[250] Ohtsu, A., et al., Bevacizumab in combination with chemotherapy as first-line therapy in advanced gastric cancer: a randomized, double-blind, placebo-controlled phase III study. J Clin Oncol, 2011. 29(30): p. 3968-76.

[251] Rapisarda, A. and G. Melillo, Overcoming disappointing results with antiangiogenic therapy by targeting hypoxia. Nat Rev Clin Oncol, 2012. 9(7): p. 378-90. 
